\title{
DOS CATECISMOS DEL SIGLO XVIII ELABORADOS POR EL ESCRIBANO NAHUATLAHTO D. LUCAS MATHEO*
}

\author{
TWO XVIIITH CENTURY CATECHISMS HANDMADE BY \\ THE “NAHUATLAHTO SCRIBE” D. LUCAS MATHEO
}

\author{
Luz María Tena Colunga \\ Universidad Nacional Autónoma de México \\ Posgrado en Estudios Mesoamericanos \\ luzmatena@gmail.com \\ ORCID: 0000-0001-9663-3029
}

\section{Resumen}

En este artículo se propone la relación existente entre la Doctrina christiana, Egerton Ms. 2898 y el Catecismo hispano-mexicano. Antes del presente trabajo, se consideraban como dos catecismos del siglo XVIII, elaborados por el escribano nahuatlahto Lucas Matheo. Como resultado de la investigación, se concluye que el primer manuscrito es el original, siendo el segundo una copia realizada por Galicia Chimalpopoca en 1877 . Antes de ser separados, ambos formaron parte de la Colección Ramírez. En esta investigación, se formulan posibles escenarios de cómo se logró desvincularlos. Se presenta también un estudio comparativo de cuestionarios aprobados para la catequesis de acuerdo con las regulaciones del siglo XVIII, a fin de identificar los modelos que se tomaron para elaborar el contenido en el Egerton Ms. 2898.

Palabras clave: Lucas Matheo; Egerton Ms. 2898; Catecismo hispano-mexicano; Galicia Chimalpopoca; Colección Ramírez; manuscritos nahuas; catecismos siglo XviII.

\begin{abstract}
In this article is demonstrated the relationship between the Doctrina Christiana, Egerton Ms. 2898, and the Catecismo hispano-mexicano. In the works prior to this article, it was believed that they were considered two different catechisms of the eighteenth century, elaborated by the "nahuatlahto scribe" Lucas Matheo. In consequence of the investigation, it is shown that the first manuscript is the original, while the second one is just a copy transcribed by Galicia Chimalpopoca in 1877. Both manuscripts were originally included in the Ramírez Collection until somebody separated them. In this document, the possible scenarios in which the disengagement was feasible are formulated. In addition, a comparative study is presented on the Catechism questionnaires approved by regulations in the 18th century, in order to specify which ones were used as models by the Egerton Ms. 2898.
\end{abstract}

Keywords: Lucas Matheo; Egerton Ms. 2898; Catecismo hispano-mexicano; Galicia Chimalpopoca; Nahua manuscripts; XviIIth century Catechisms.

* Agradezco y hago constar que la presente investigación y el apoyo para el desarrollo de la misma en el lugar del repositorio fue posible gracias a que conté con el apoyo económico de la Dirección General de Estudios de Posgrado de la Universidad Nacional Autónoma de México, a través de su Programa de Becas. Agradezco a Patrick Johansson, Ascensión Hernández Triviño, Antonio Rubial García, Berenice Alcántara Rojas, Leticia Pérez Puente, a los editores de esta publicación y a los dos dictaminadores anónimos del presente artículo sus valiosas orientaciones. 
Información del artículo

Recibido: 5 de mayo de 2019.

Aceptado: 30 de octubre de 2019.

DOI: $10.22201 /$ iih.24486922e.2020.62.69587

En el siglo XVI, el programa de evangelización a indígenas tuvo como obstáculo la diversidad de lenguas que se hablaba en el territorio que la Corona española denominó virreinato de la Nueva España. En una primera etapa, los frailes misioneros recurrieron a la explicación de los conceptos esenciales por medio de imágenes pintadas en lienzos. ${ }^{1}$ Posteriormente aprendieron las principales lenguas, sobre todo el náhuatl hablado por los gobernantes de la Triple Alianza, quienes controlaban tributariamente los territorios de lo que hoy en día conocemos como México.

El primer catecismo impreso en México ${ }^{2}$ es la Breve y más compendiosa doctrina christiana en lengua mexicana y castellana del primer obispo de la Nueva España, fray Juan de Zumárraga, quien en 1539 lo manda imprimir a su costa en la Ciudad de México. Sin embargo, también continuaron en uso los catecismos pictográficos y los manuscritos en las lenguas autóctonas, para la enseñanza de los principios básicos de la religión católica. En las regulaciones que se hicieron en los concilios provinciales mexicanos, se tomó en cuenta el material manuscrito para adoctrinar a los indígenas, a fin de que no circulara sin que fuese aprobado.

Los catecismos en imágenes o pictográficos desempeñaron un papel muy importante para la catequización del indígena. La mayoría de los ejemplares que han sobrevivido al paso del tiempo son considerados de los siglos XVII a XIX. La datación de ejemplares del siglo XVI provoca controversia entre los especialistas que únicamente consideran a dos con posibilidad de tener esa antigüedad. La mayoría de ellos se encuentra en repositorios en el extranjero. En 1975 John B. Glass ${ }^{3}$ reportaba 35 y señalaba como perdidos algunos otros ejemplares que fueron descritos en publicaciones del

${ }^{1}$ Gerónimo de Mendieta, Historia eclesiástica indiana, 1a. reimp. (México: Consejo Nacional para la Cultura y las Artes; Ediciones Cien, 2002), 402. Esteban J. Palomera, S. J., Fray Diego Valadés, ofM, evangelizador humanista de la Nueva España. El hombre, su época y su obra (México: Universidad Iberoamericana, Departamento de Historia, 1988), 420.

${ }^{2}$ Román Zulaica Gárate, Los franciscanos y la imprenta en México en el siglo XVI (México: Universidad Nacional Autónoma de México, Instituto de Investigaciones Bibliográficas, 1991), 26.

${ }^{3}$ John B. Glass, “A Census of Middle American Testerian Manuscripts”, en Handbook of Middle American Indians. 14/15. Guide to Ethnohistorical Sources, Parts Three and Four, ed. 
siglo XVIII y XIX. En 1985, Anne Whited Normann registra los de probada existencia (incluyendo los que se consideran copias) y los perdidos, presentando un total de $42 .{ }^{4}$ El censo más reciente (2017) es de Elizabeth Hill Boone, Louise M. Burkhart y David Tavárez, quienes presentan un cuadro de los catecismos pictográficos en repositorio a la fecha, en los que se cuentan un total de 37.5

La Doctrina Christiana Egerton Ms. 2898 (en adelante Egerton Ms. 2898) es uno de los catecismos pictográficos que se han conservado hasta la fecha y es el único del denominado Grupo Egerton que se tomó en cuenta en esta investigación. ${ }^{6}$

El objetivo del presente trabajo es demostrar la relación entre el Egerton Ms. 2898 y el Catecismo hispano-mexicano. Por años se había considerado que éstos sólo tenían en común haber sido elaborados por D. Lucas Matheo en agosto de 1714. Como resultado de esta investigación, se demuestra que el primer manuscrito es el original, siendo el segundo una copia elaborada por Galicia Chimalpopoca en 1877. Ambos manuscritos formaron parte de la Colección Ramírez, hasta que fueron desvinculados y terminaron en diferentes repositorios.

Gracias a las facilidades que otorga el Museo Británico de Londres para el estudio del Egerton Ms. $2898,{ }^{7}$ se pudieron observar y fotografiar detalles que coadyuvaron a la identificación del documento como parte de la Colección Ramírez.

En la metodología desarrollada se exploraron diferentes líneas de investigación. Una de ellas fue la identificación del documento, tratando de encontrar la filiación del escribano D. Lucas Matheo, quien había sido considerado en la historiografía como un posible tlacuilo o dibujante y escribano

de Robert Wauchope, Howard F. Cline, Charles Gibson y H. B. Nicholson (Austin, Texas: University of Texas Press, 1975), 281-296.

${ }^{4}$ Anne Whited Normann, “Testerian Codices: Hieroglyphic Catechisms for Native Conversion in New Spain” (PhD diss. Tulane University, New Orleans, 1985), 27-29.

${ }^{5}$ Elizabeth Hill Boone, Louise M. Burkhart y David Tavárez, Painted Words: Nahua Catholicism, Politics and Memory in the Atzaqualco Pictorial Cathecism (Washington, D. C.: Dumbarton Oaks, 2017), 22-29. Los autores tomaron en cuenta los censos previos, así como los catecismos que después de 1985 ya fueron fácilmente localizables.

${ }^{6}$ Normann, “Testerian Codices...”, 129, agrupa en su tesis a los catecismos que muestran características semejantes y enlista tres catecismos como Grupo Egerton; el Egerton Ms. 2898, que es el original, y dos copias derivadas de éste; Doctrina cristiana en geroglíficos y las copias o notas fragmentadas realizadas por Chimalpopoca Galicia en el siglo xıx. Después de su investigación, se les empezó a nombrar como Grupo Egerton.

${ }^{7}$ Agradezco a James Hamill las facilidades otorgadas para tener acceso al documento. 
indígena que copió este manuscrito ${ }^{8}$ La firma de D. Lucas contiene elementos de identificación de escribano autorizado por el rey, por lo que en los inicios de la investigación se realizó el análisis de la firma tratando de dar respuesta al porqué un indígena podía haber utilizado signos de escribano autorizados por el rey, siendo que ni mestizos ni indígenas podían ocupar esos cargos. La investigadora Louise M. Burkhart lo identificó como indígena en el Códice Kaska. ${ }^{9}$ Sin embargo, en ese documento, firmó de manera diferente y el análisis de la firma en el Egerton Ms. 2898 arrojó elementos que fueron determinantes para concluir que es el manuscrito original, y el Catecismo hispano-mexicano una copia. Los detalles se presentarán más adelante, en el inciso correspondiente.

Otra línea de investigación fue la paleografía, traducción y estudio histórico del cuestionario de catequización. Este elemento es un aspecto más dinámico que las oraciones, debido a que, según se pudo apreciar, cada autor desde los inicios de la evangelización, iba agregando o quitando elementos explicativos, y sirvió para obtener otros datos hasta hoy no abordados.

Por ejemplo, se revisaron los materiales impresos desde el siglo XVI hasta el XVIII, y se encontraron en los concilios provinciales muchas de las razones por las cuales, aunque hubiese catecismos traducidos e impresos en lengua náhuatl desde el siglo xvi, el Egerton Ms. 2898 no los utilizó.

Asimismo, se estudió la regulación y las condiciones de la época que hicieron posible que dichos catecismos continuaran en uso prácticamente hasta finales de la época colonial, como se presentará más adelante.

\footnotetext{
${ }^{8}$ Joaquín Galarza, Doctrina christiana: Méthode pour l'analyse d'un manuscrit pictographique mexicain de xviIIe siècle, avec application à la première prière le Pater Noster, con la colaboración de Aurore Monod Becquelin (París: Société d'Ethnographie, 1980); Normann, “Testerian Codices...”; Bérénice Gaillemin, “L’art ingénieux de peindre la parole et de parler aux yeux. Élaboration et usages des catéchismes en images du Mexique (xvie-Xıxe siècles)" (tesis de doctorado en Etnología, Université Paris Ouest Nanterre La Défense, 2013); Uta Berger, Gebetbücher in mexikanischer Bilderschrift: Europaische Ikonographie im Manuskript Egerton 2898 aus der Sammlung des Britischen Museum, London (Münster: LIT, 2002). Estas obras son las más importantes y se repiten como referencia en innumerables libros, artículos y tesis. En relación con Berger, consulté el artículo que escribió en inglés, como se verá más adelante.

${ }^{9}$ Louise M. Burkhart, "2014 Presidential Address: Christian Salvation as Ethno-Ethnohistory: Two Views from 1714”, Ethnohistory 63, n. 2 (abril 2016): 221, doi:https://doi. org/10.1215/00141801-3455267. Agradezco al doctor David Tavárez haberme informado de la existencia del documento.
} 
Siendo que el Catecismo hispano-mexicano, manuscrito elaborado por Galicia Chimalpopoca, se consideraba como "posiblemente relacionado" en la historiografía mencionada anteriormente, y dado que eran del mismo escribano y del mismo siglo, era importante cotejar firmas y elementos entre ambos documentos, como parte de la metodología para la identificación del Egerton Ms. 2898. Las pistas que las líneas de investigación iban arrojando, por cotejo de firmas y elementos usados por el escribano, nos proporcionaron los elementos iniciales, a través de los cuales, haciendo una comparación plena de ambos documentos, se pudo concluir que el Catecismo hispano-mexicano es la transcripción manuscrita del Egerton Ms. 2898.

La traducción al español que se presenta (anexo 1) no es la que se podría encontrar en un catecismo impreso. La intención es mostrar la probable visión del indígena, que en su lengua náhuatl atesora un crisol cultural. Patrick Johansson señala: "La lengua entraña la cultura; es la forma de expresar cómo se percibe una emoción, un acontecimiento, la visión de todo lo perceptible e imperceptible". ${ }^{10}$

Cabe señalar que la identificación plena del lugar de origen de este documento y muchos otros detalles aún no ha sido posible conocerlos con certeza, a pesar de que en esta investigación se haya determinado que ambos estuvieron juntos en la Colección Ramírez. En este trabajo, se presentan posibles respuestas de cómo se logró desligarlos y cómo terminaron en diferentes repositorios.

\section{EL EGERTON MS. 2898}

El documento de referencia se encuentra en resguardo en el British Museum de Londres, que lo adquirió en 1911 y forma parte del Fondo Farnborough. ${ }^{11}$ Es un pequeño libro encuadernado rústicamente en una piel suave color

${ }^{10}$ Comunicación personal.

${ }^{11}$ British Museum Catalogue of Additions to the Manuscripts 1911-1915, 2 v. (London: British Museum, 1925), 405. Fue clasificado como parte de la colección de manuscritos que Sir Francis Henry Egerton, conde de Bridgewater, legó a su muerte, junto con un fondo (Bridgewater) para la compra de manuscritos históricos. Sin embargo, el Egerton Ms. 2898, comprado en 1911 por el Museo Británico, fue adquirido con un segundo fondo (Farnborough) que el primo del conde, el barón Farnborough, legó a su muerte, para continuar con la compra de manuscritos históricos. 
marrón, de $22.7 \mathrm{~cm}$ de alto por $34.4 \mathrm{~cm}$ de ancho. ${ }^{12} \mathrm{El}$ manuscrito consta de 30 folios. El primero contiene una pequeña introducción manuscrita en lengua náhuatl y los 29 restantes presentan pictografías que combinan elementos de la religión católica, con componentes de tradición indígena. Aprovechando espacios entre imágenes, agregaron las oraciones o explicaciones correspondientes a conceptos del catecismo. Todo ello manuscrito en lengua náhuatl.

El cuestionario para la catequización muestra imágenes y un diálogo entre el sacerdote y un indígena que responde certeramente a las 29 preguntas.

En el folio 29v del documento, al final de las pictografías correspondientes al Confiteor se insertó en forma manuscrita en lengua náhuatl, una especie de despedida en la que se indica la terminación de esta doctrina cristiana. Ahí mismo se observa la fecha a la cual se le borraron (aparentan-

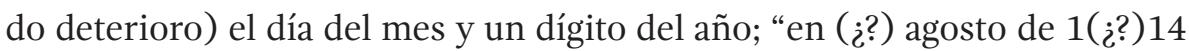
años", la firma del escribano y su signo, que a la letra se lee "Dom. Locas Matheo escrivano". A la firma le acompañan todos los signos de identificación del oficio de escribano novohispano.

\section{Lugar de procedencia}

En el Catálogo de adquisiciones del Museo Británico no se identifica su procedencia. ${ }^{13}$ Glass establece que posiblemente formó parte de la colección de Felipe Sánchez-Solís y de la Colección del Barón Von Waecker-Götter. ${ }^{14}$ Uta Berger comparte esa opinión basándose en que el museo adquirió varios documentos de esa colección en el mismo año. ${ }^{15}$ Normann consideró que provenía de la colección Sánchez-Solís, con base en una descripción de Orozco y Berra de $1877 .{ }^{16}$

12 “Egerton Ms. 2898”, The British Museum, Departamento de África, Oceanía y las Américas, consultado el 11 de julio de 2018, https://research.britishmuseum.org/research/ collection_online/collection_object_details/collection_image_gallery.aspx?partid=1\&assetid=218529001\&objectid $=649998$.

${ }^{13}$ British Museum Catalogue, 411.

${ }^{14}$ Glass, "A Census of Middle American", 290.

${ }^{15}$ Uta Berger, Mexican Painted Manuscripts in the United Kingdom, Occasional Paper, n. 91 (Londres: British Museum, 1998), 80.

${ }^{16}$ Normann, “Testerian Codices”, 132. 
La metodología empleada en esta investigación consistió en indagar acerca de las colecciones y vendedores de las mismas y buscar, en lo posible, el camino que recorrió hasta llegar a su repositorio. Se investigó en el catálogo de 1911 a fin de conocer los documentos que sí eran reconocidos como parte de una colección; por ejemplo, el Egerton Ms. 2895, que también fue adquirido con el Fondo Farnborough, e identificado como parte de la colección de Sánchez-Solís. No se encontró una razón que justificara que el Egerton Ms. 2898 no fuera registrado en ese catálogo como parte de una colección, si hubiera habido algún elemento que lo determinara así. A lo anterior se suma que otros manuscritos mexicanos que se compraron en el mismo año (por ejemplo; Egerton Ms. 2896, Fondo Farnborough) tampoco tienen identificadas las colecciones de las que provienen. En el mismo catálogo del Museo Británico se aprecia que se compraron manuscritos al comerciante londinense Bernard Quaritch. Por John Frederick Schwaller se sabe que ese comerciante vendió algunos manuscritos de la Colección de Fernández del Castillo, mismos que en un inicio formaron parte de la Colección Ramírez en la subasta de Londres de $1880 .{ }^{17}$ De ahí se encontró la posible conexión de origen con el manuscrito Catecismo hispano-mexicano, como se presenta más adelante.

\section{El CATECismo HiSPANO-MEXICANO}

Este catecismo se encuentra en resguardo en la Biblioteca Bancroft; ${ }^{18}$ mide $23 \mathrm{~cm}$ y está encuadernado en piel negra con bordes en tela azul. Es una copia que realizó Faustino Galicia Chimalpopoca en 1877. El documento es un manuscrito a dos columnas que no contiene imágenes. La columna del lado izquierdo está escrita en lengua náhuatl y la del lado derecho presenta la traducción al castellano. Tiene una extensión total de 48 folios.

${ }^{17}$ John Frederick Schwaller, "Guías de manuscritos en náhuatl, conservados en Newberry Library (Chicago), The Latin American Library of Tulane University, The Bancroft Library, University of California, Berkeley”, Estudios de Cultura Náhuatl, n. 18 (1986): 361.

${ }^{18}$ Bancroft Library, University of California, Berkeley, H. H. Bancroft Collection, Ms. M-M 465, última consulta julio 2018, http://oskicat.berkeley.edu/record=b11233116 S1. Agradezco a Prescott Muir, por haberme proporcionado el Catecismo hispano-mexicano para mi investigación. 
Lugar de procedencia

El documento de referencia procede de la Colección Ramírez, pero se desconoce su lugar de origen. La Biblioteca Bancroft adquirió este Catecismo hispano-mexicano del lote de manuscritos de Edward Ayer (comerciante norteamericano), que a su vez provenían del comerciante de manuscritos y libros raros de Londres, Bernard Quaritch. La subasta de tan importantes manuscritos se realizó en Londres en 1880.

Schwaller indica que, en dicha subasta, el entonces destacado estudiante norteamericano Henry Stevens compró manuscritos para la Biblioteca Bancroft, ${ }^{19}$ pero también compró otros para la biblioteca del Museo Británico (British Museum). Hasta el momento no se dispone de una relación de cómo los distribuyó. Se sabe que Steven ${ }^{20}$ se convirtió en comerciante de libros $\operatorname{raros}^{21}$ y que invertía parte de sus ingresos para la compra personal de este material. Su biógrafo resalta la infortunada bancarrota en que se encontró en 1845. En la subasta de 1880 pudo haber comprado los dos manuscritos y por motivos comerciales separarlos, descontextualizarlos y vender el Catecismo hispano-mexicano a Ayer. También Quaritch podría haberlos separado para esa subasta.

Cabe señalar que al Egerton Ms. 2898 en un aparente deterioro se le borró el segundo dígito del año 1714 e ingresó al Museo Británico en 1911, como un documento que probablemente era de 1614. Así resultó más atractivo por su antigüedad y quedó desconectado del Catecismo hispanomexicano, que después de la subasta realizada en Londres en 1880 ingresó a la Biblioteca Bancroft con muchos otros manuscritos de la Colección Ramírez.

Schwaller comenta que el original estaba en el Museo Nacional y que Ramírez y Chimalpopoca corroboraron el original del Catecismo hispanomexicano, que ahora conocemos que es el Egerton Ms. 2898. ${ }^{22}$ Se sabe lo interesado que estuvo siempre Fernando Ramírez por preservar y dotar al país de una historia fundamentada; sin embargo, al catecismo no le agregaron (¿o se extravió?) una nota aclarando en dónde fue utilizado.

${ }^{19}$ Schwaller, "Guías de manuscritos en náhuatl", 361.

${ }^{20}$ Edward Holley, reseña de American Rare Book Dealer in London (1845-1886), de Henry Stevens of Vermont, consultado en marzo 2018, http://hdl.handle.net/2142/37740.

21 "American rare book dealer." Así es como clasificaban los códices y manuscritos en idiomas originarios de América. La traducción es mía.

22 Schwaller, "Guías de manuscritos en náhuatl", 363. 
Ernesto de la Torre Villar comenta de Ramírez: "como conservador y director del Museo Nacional se preocupó por acrecentar su documentación, aprovechando para ello su puesto de interventor de las bibliotecas y archivos de los conventos extinguidos". ${ }^{23}$

En ese orden de asuntos y debido al contenido de oraciones de procedencia jesuita y a elementos en imágenes, tales como el "arpa de dos órdenes" (véase la figura 1), instrumento que Bérénice Gaillemin muestra que era utilizado por los jesuitas en los siglos XVII y XVIII, ${ }^{24}$ podría pensarse que el Egerton Ms. 2898 tal vez hubiera formado parte de una biblioteca o archivo de los sacerdotes jesuitas.

Sin embargo, se coincide con todos los investigadores que lo han estudiado en que tiene elementos de la orden de los dominicos. Los primeros en evidenciarlo fueron Joaquín Galarza y Aurore Monod Becquelin, ${ }^{25}$ quienes también identificaron que el Egerton Ms. 2898 fue copiado por el tlacuilo indígena de un manuscrito previo. Hacen falta elementos contundentes para identificar a la orden que elaboró el documento primario. El Archivo Histórico de Notarías de la Ciudad de México (expedientes de notarios de la Colonia) y el Archivo General de la Nación no contienen un listado de todos los escribanos eclesiásticos. ${ }^{26}$

\section{EL CATECISMO PICTOGRÁFICO DE TRADICIÓN INDÍGENA EGERTON MS. 2898}

No se considera adecuada la clasificación del Egerton Ms. 2898, como un catecismo testeriano, por las razones que se exponen a continuación.

${ }^{23}$ Ernesto de la Torre Villar, "Vida y obra de José Fernando Ramírez”, en Obras históricas, Tomo I. Época prehispánica, de José Fernando Ramírez (México: Universidad Nacional Autónoma de México, Coordinación de Humanidades, Instituto de Investigaciones Históricas, 2001), 79, última consulta 1 de julio de 2018 http://www.historicas.unam.mx/publicaciones/publicadigital/libros/obras_historicas/oht01/388_04_02_VidaObra.pdf.

${ }^{24}$ Gaillemin, "L’art ingénieux”, 603.

${ }^{25}$ Galarza, Doctrina christiana.

${ }^{26}$ Archivo General de Notarías, Catálogo de Protocolos del Archivo General de Notarías de la Ciudad de México, Fondo Antiguo 1525-1902. Archivo General de la Nación, México, Instituciones Coloniales, Gobierno Virreinal, SE045 Escribanos, Escribanos Reales, Escribanos Eclesiásticos, Escribanos de Provincia y Escribanos de Número, Fecha(s) 16001841. 


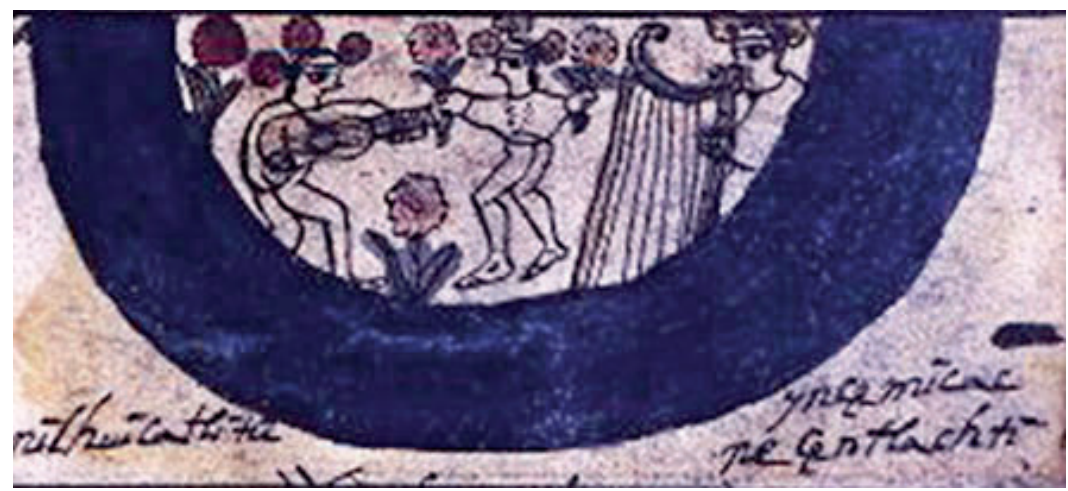

Figura 1. Folio 7r (fragmento) Egerton Ms. 2898. Arpa de dos órdenes. (C) The Trustees of the British Museum

Joseph Marius Alexis Aubin, famoso coleccionista e investigador de la cultura prehispánica y colonial mexicana, ${ }^{27}$ propuso que a las imágenes que no tenían un antecedente prehispánico se les podía considerar "testerianas", aludiendo al fraile Jacobo de Testera, quien en los comienzos de la evangelización en el territorio de la Nueva España mostraba a los neófitos imágenes de la religión católica en lienzos. Aubin también dijo que es difícil distinguir las imágenes imitativas de origen europeo de las que verdaderamente presentan origen indígena. Esto dio pie a que a los catecismos en imágenes se les agrupara como "catecismos testerianos", suponiendo que Aubin había denominado así a todos los catecismos pictográficos. Él solamente mencionó que en las doctrinas es difícil separar las copias de imágenes de origen europeo de las de procedencia indígena y que la imagen que no tiene antecedente prehispánico es testeriana.

El Egerton Ms. 2898 contiene imágenes de tradición indígena y sin embargo se le ha considerado testeriano. Como se puede apreciar en la imagen presentada en la figura 2, se tienen elementos de tradición indígena, para complementar por medio de un "diálogo pictórico" los conceptos que la palabra escrita no podría explicar, haciéndolo más comprensible y, a la vez, más cercano a los elementos tradicionales de los indígenas.

No siendo el objetivo principal de este trabajo el análisis de la imagen, de entre todos los elementos que se pueden interpretar en la figura $2 \tan$

${ }^{27}$ Joseph Marius Alexis Aubin, Memorias sobre la pintura didáctica y la escritura figurativa de los antiguos mexicanos, 1a. reimp. (México: Universidad Nacional Autónoma de México, Instituto de Investigaciones Históricas, 2009), 26-27. 


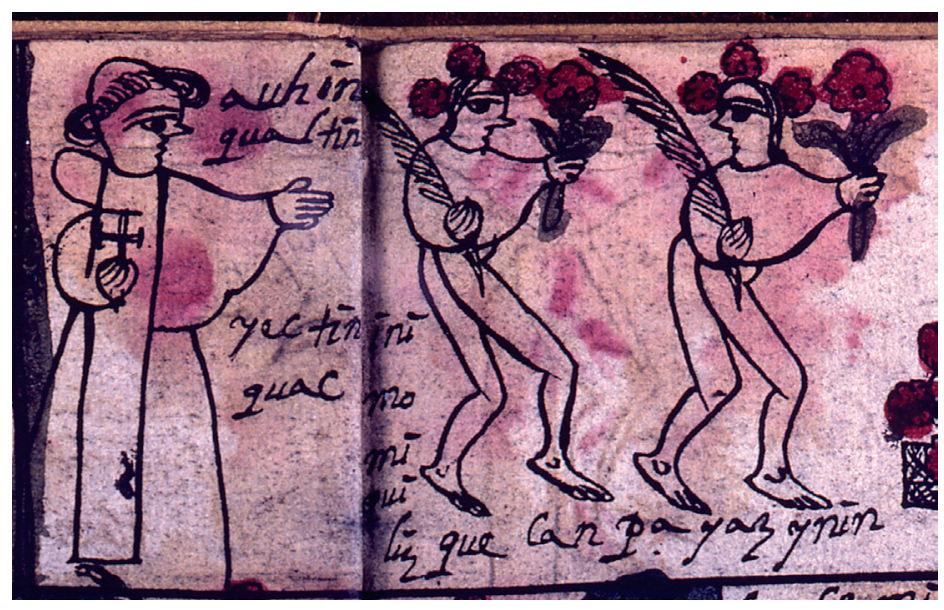

Figura 2. Folios 17v y 18r (detalle).

Catecismo del Egerton Ms. 2898. (C) The Trustees of the British Museum

sólo mencionaremos dos que portan los personajes indígenas: las palmas (mano derecha) y las flores en la mano izquierda y adornando la cabeza. Entre los principales atributos de los santos mártires católicos se encuentran la palma y una corona de flores. En este caso las tres flores de la cabeza no tienen parecido con la corona de las imágenes católicas; se colocaron las flores a la usanza indígena. Según León-Portilla, en un poema de Nezahualcóyotl se asevera que las flores son llevadas a donde mora la divinidad, que es el lugar de su origen. ${ }^{28} \mathrm{Al}$ ver esta imagen con estos atributos, se cumplían dos funciones: los indígenas aprendían que la palma era para los buenos cristianos, los que habitaban con Dios en el cielo y al mismo tiempo conservaban su tradición de la flor, que era utilizada para agradar a sus dioses, relacionando así estos dos elementos.

Se considera importante la descalificación del término "testeriano" que han propuesto Bérénice Gaillemin, ${ }^{29}$ Elizabeth Hill Boone, Louise M. Burkhart y David Tavárez ${ }^{30}$ en los catecismos que muestran tradición indígena y se propone que en adelante se les denomine catecismos pictográficos de tradición indígena.

${ }^{28}$ Miguel León-Portilla, La filosofía náhuatl estudiada en sus fuentes, 10a. ed. (México: Universidad Nacional Autónoma de México, Instituto de Investigaciones Históricas, 2006), 146.

${ }^{29}$ Comunicación personal.

${ }^{30}$ Boone, Burkhart y Tavárez, Painted Words, 30. 


\section{EL CUESTIONARIO DE CATEQUIZACIÓN}

EN EL EGERTON MS. 2898 Y LA ATRIBUCIÓN DE LA AUTORÍA

\section{AL JESUita BARTOLOMÉ CASTAÑo}

En 1980 Galarza y Monod Becquelin atribuyeron al jesuita Bartolomé Castaño el cuestionario de catequización del Egerton Ms. 2898 identificándolo como "Dialoguito de la palabra de Dios del padre Castaño". ${ }^{31}$

La idea de que el cuestionario tuviera esa denominación de "Dialoguito del padre Castaño” en el Egerton Ms. 2898 se disipó con la consulta del Catálogo de adquisiciones de 1911 del Museo Británico de Londres. En la descripción general se menciona únicamente como "catecismo", sin poner el autor del mismo.

El sacerdote jesuita Bartolomé Castaño nació en villa de Santarém en Portugal. Era un excelente orador y fue muy apreciado por las demás órdenes religiosas y el clero secular de la Nueva España, ${ }^{32}$ lo cual ayudó a que su catecismo fuese recomendado desde su elaboración. En 1644 publicaron su Catecismo breve de lo que precisamente debe saber el cristiano. ${ }^{33}$

Se sabe que el catecismo del jesuita Gerónimo Ripalda era utilizado desde su creación en España en el siglo xviı y que tuvo gran aceptación en la Nueva España. No obstante, la importancia del elaborado por Castaño se debe a que lo tradujo en diversas lenguas originarias y a su labor directa en comunidades indígenas.

Burkhart tomó la línea de investigación del catecismo de Castaño, como modelo en varios catecismos pictográficos, en un estudio que publicó acerca de la catequesis en Nueva España. ${ }^{34}$ Explica que era útil porque era muy breve y muy fácil de memorizar, pues tan sólo tenía 24 preguntas.

La importancia del material de Castaño sugería que podría haber sido utilizado como modelo en el Egerton Ms. 2898. Sin embargo, se realizó un estudio con la finalidad de comprobar en la medida de lo posible esta premisa, que también coadyuvó a que se pudiera determinar que el Egerton

${ }^{31}$ Galarza, Doctrina christiana, 19. No explicaban tal atribución.

32 Thomás de Escalante, Breve noticia de la vida exemplar y dichosa muerte del venerable padre Bartholomé Castaño en la Compañía de Jesús (México: Juan Rivera en el Pedradillo, 1679), 5 y 45.

${ }^{33}$ Louise M. Burkhart, “The 'Little Doctrine’ and Indigenous Cathechesis in New Spain”, Hispanic American Historical Review, n. 94 (2014): 174, menciona y ratifica que no hay manera de conseguir el de 1644.

${ }^{34}$ En: “The 'Little Doctrine'”, Burkhart presenta una exposición de los principales catecismos desde el siglo XVI al XVIII, e incluye en su hipotético corpus al Egerton Ms. 2898, 174. 
Ms. 2898 y el Catecismo hispano-mexicano estuvieron juntos, como se expone en un apartado más adelante. Para este estudio, era importante conocer las regulaciones, que se presentan a continuación.

\section{REGULACIONES PARA LOS CATECISMOS MANUSCRITOS EN LENGUAS ORIGINARIAS}

Los esfuerzos de evangelización se cristalizaron al inicio en doctrinas manuscritas y posteriormente en algunas ya impresas para catequizar a los indígenas en sus lenguas originarias. Sin embargo, en los concilios se buscó que hubiese uniformidad y certeza de transmitir los conceptos correctamente, lo cual al parecer descalificó en cierta forma a los catecismos anteriores a las regulaciones.

En los tres concilios provinciales mexicanos celebrados en el siglo XVI $(1555,1565$ y 1585$)$ se dictaron las regulaciones para los catecismos manuscritos en lenguas originarias de la Nueva España.

En una clara alusión a que no había uniformidad en el material para la enseñanza de la doctrina a los indígenas, en la constitución IV del primer concilio se ordenó que se hicieran doctrinas para los indios. ${ }^{35}$ Específicamente, se solicitaron dos: una breve, sin notas explicativas, y otra con declaración sustancial de los artículos de la fe, mandamientos, pecados mortales y con la declaración del Pater Noster. Asimismo, se estableció que se tradujeran en muchas lenguas y se imprimieran. Este material, era únicamente para que los sacerdotes que estuvieran a cargo de la enseñanza de las doctrinas tuviesen contenidos similares.

Por lo que concierne al tratamiento específico de las doctrinas escritas en lengua indígena, en la constitución LXIX se solicita: "que ninguna doctrina se traduzca en lengua de indios si no fuere examinada por clérigo o religioso que entienda la lengua en que se traduce". ${ }^{36}$

${ }^{35}$ Leticia Pérez Puente, Enrique González González y Rodolfo Aguirre Salvador, “Constituciones de el Arzobispado y provincia de la muy insigne y muy leal Ciudad de Tenochtitlan, México, de la Nueva España Concilio Primero", en Concilios provinciales mexicanos. Época colonial, coord. de María del Pilar Martínez López-Cano (México: Universidad Nacional Autónoma de México, Instituto de Investigaciones Históricas, 2004), 6-7, última revisión 11 de julio de 2018, http://www.historicas.unam.mx/publicaciones/publicadigital/libros/concilios/docs/1er2do_002.pdf.

${ }^{36}$ Pérez Puente, González González y Aguirre Salvador, "Constituciones de el Arzobispado", 80 . 
Ante la celeridad que mostró el arzobispo Montúfar para la promulgación de las regulaciones emanadas de este primer concilio, no se guardaron las debidas normas para su aprobación. En ese sentido, circularon impresas y sin aprobación, sirviendo únicamente como referencia. ${ }^{37}$

Para el segundo concilio se hizo una depuración de las disposiciones del primero, anulando únicamente las que no fueran acordes con los decretos tridentinos, y se agregaron nuevas disposiciones. ${ }^{38}$ Es así que, además de la antes citada constitución LXIX del primer concilio en relación con los manuscritos en lenguas originarias, se agrega el estatuto xxıII, en el que sólo se les permite a los indígenas poseer su doctrina cristiana, previamente autorizada: "que no se permita a los indios tener sermonarios, nóminas, ni otra cosa de escritura escrita de mano, salvo la doctrina cristiana aprobada por los prelados y traducida por los religiosos lenguas, conforme a las sinodales de el dicho arzobispado y provincia". ${ }^{39}$

Sin embargo, el arzobispo Montúfar no presentó una doctrina cristiana ya reglamentada y especializada para los indígenas en el primer concilio ni en el segundo.

Las doctrinas impresas no estaban al alcance económico de la población indígena en general. En este orden de asuntos, sería comprensible y muy probable que algunas de las doctrinas cristianas manuscritas hubieran sido elaboradas en papel de fabricación doméstica hasta el siglo XVIII. ${ }^{40}$ Es posible que haya sido el caso del papel del Egerton Ms. 2898. ${ }^{41}$ Por no tener las marcas del papel controlado por la Corona española (papel

${ }^{37}$ Leticia Pérez Puente, Enrique González González y Rodolfo Aguirre Salvador, "Estudio introductorio. Los concilios provinciales mexicanos primero y segundo”, en Concilios provinciales, 19.

${ }^{38}$ Pérez Puente, González González y Aguirre Salvador, "Estudio introductorio”, 22.

39 Pérez Puente, González González y Aguirre Salvador, "MDLXv años: Concilio Provincial que se celebró en la Ciudad de México el dicho año de 1565 años. Concilio Segundo”, en Concilios provinciales, 11.

${ }^{40}$ Miguel León-Portilla, Cantares mexicanos I: Estudios (México: Universidad Nacional Autónoma de México; Fideicomiso Teixidor, 2011), 52-96. Ascensión Hernández de León-Portilla expone en el estudio codicológico la manufactura del papel, y nos dice que desde 1560 existía un molino de papel en el Convento Agustino de Culhuacán (66).

${ }^{41}$ Tomando en cuenta la duda de Juan José Batalla y lo explicado por Hernández de León-Portilla, examiné personalmente el papel y noté que se distinguen líneas, que pudieran ser hilos metálicos de la formadera o bastidor, posiblemente de confección novohispana, dado que aprendieron la técnica europea, abaratando así los insumos. Por esta razón podría ser de manufactura doméstica. 
filigrana europeo) y estando descontextualizado de la Colección Ramírez, provocó dudas de su origen al especialista en códices Juan José Batalla Rosado. $^{42}$

El Tercer Concilio Provincial Mexicano celebrado en 1585 fue convocado por el arzobispo, también virrey en funciones de la Nueva España, Pedro Moya de Contreras.

Los títulos III y IV del primer libro hacen notar la elaboración de un catecismo aprobado y formado por el sínodo. Hay noticias de que sí se elaboró uno. Incluso se conoce que fue redactado en su totalidad por el jesuita Juan de la Plaza, pero no se imprimió porque para 1622 (año de la impresión del tercer concilio) el Catecismo de Ripalda ya tenía amplia difusión y entonces no se juzgó necesario. ${ }^{43}$

Las doctrinas cristianas en lenguas indígenas manuscritas no se mencionan específicamente en este tercer concilio. No obstante, con el Egerton Ms. 2898 se comprueba que siguieron siendo utilizadas con las regulaciones del primer concilio y del segundo durante los siglos XVII y XVIII. Las regulaciones también continuaron vigentes hasta el siglo XIX, según se aprecia en la siguiente cita:

De hecho el tercer concilio, por la amplitud de los temas tratados y por su vigencia, marcó decisivamente a la Iglesia novohispana. Como se verá, el IV concilio no obtuvo ni la ratificación real ni la pontificia, por lo que los decretos del tercer concilio mantuvieron su vigencia hasta 1896 en la arquidiócesis de México, año en que se celebró el v concilio provincial mexicano... ${ }^{44}$

Las doctrinas manuscritas y en imágenes continuaron en uso hasta el siglo xIx. Aubin afirma que había un sacerdote que enseñaba mediante catecismos en imágenes y que no deseaba que los indios aprendieran castellano

${ }^{42}$ Juan José Batalla Rosado, "Problemática sobre la datación de los catecismos en pictogramas o códices testerianos", en Del saber ha hecho su razón de ser... Homenaje a Alfredo López Austin, ed. de Ángela Ochoa y Eduardo Matos Moctezuma (México: Instituto Nacional de Antropología e Historia; Universidad Nacional Autónoma de México, 2017), II:53.

${ }^{43}$ María del Pilar Martínez López-Cano, Elisa Itzel García Berumen y Marcela Rocío García Hernández, “Estudio introductorio. Tercer Concilio Provincial Mexicano (1585)”, 15, consultado en marzo 2018, http://www.historicas.unam.mx/publicaciones/publicadigital/ libros/concilios/docs/3er_001.pdf.

${ }^{44}$ Pérez Puente, González González y Aguirre Salvador, “Estudio introductorio”, 2. 
por miedo a que éstos se corrompieran con el contacto con las letras europeas, e incluso se castigaba al indio que hablaba español. ${ }^{45}$

En suma, las regulaciones para los pequeños libros manuscritos de catequización para los indígenas se gestaron del primer al tercer concilio provincial mexicano en el siglo xvi, siendo que deseaban uniformizar el material, y que no circularan las que no hubieran sido traducidas por clérigos con dominio de la lengua originaria y revisadas en su totalidad para su aprobación. La idea era producir un catecismo que fuera igual para todos los indígenas y, a la vez, que fuese breve y fácil de memorizar.

\section{PRINCIPAlES CATECISMOS “BREVES" ACEPTADOS PARA SU CIRCULACIÓN EN LENGUAS INDÍGENAS DURANTE LOS SIGLOS XVII, XVIII Y XIX. LA INFLUENCIA Del Catecismo Del Padre Castaño}

Como ya se ha expuesto, el Catecismo y exposición breve de la doctrina cristiana del jesuita Gerónimo Ripalda fue el de mayor circulación y aceptación para la enseñanza de las doctrinas en la Nueva España, desde su publicación en España en 1618. Es decir, antes del de Castaño en 1644.

Hacia finales del siglo XviI (1689), se publicó el Catecismo de Antonio Vázquez Gastelu, con un título muy parecido al del de Castaño; Catecismo breve que precisamente debe saber el cristiano, con 24 preguntas y respuestas. Comparando el cuestionario en lengua náhuatl de Gastelu y el del Egerton Ms. 2898 se observa, en términos generales, que ambos están escritos en náhuatl clásico y expresan los mismos conceptos básicos utilizando una redacción diferente. Por ejemplo, en el Egerton la pregunta ¿Cuantos dioses hay?, ¿Auh quezquintin in teteo?, es más directa, y en Gastelu, ¿ Tla xinech molhuili quezquintin in Teteo?, pregunta lo mismo, pero utilizando "xinech molhuili" como forma reverencial.

El aumento de 24 a 29 preguntas básicamente se da en el Egerton Ms. 2898 porque se describe un poco más a Santa María y a los ángeles. Gastelu fue catedrático de lengua náhuatl y en su catecismo no se mencionan autorías. ${ }^{46}$

${ }^{45}$ Aubin, Memorias, 32-33. En la nota 58 al pie de la página 33. Se refería al padre Pérez, quien en 1834 logró imprimir su catecismo en lengua otomí. Además, comenta su relación académica de estudio de imágenes con el padre Pérez.

${ }^{46}$ Antonio Vázquez Gastelu, Catecismo breve que precisamente debe saber el cristiano. Reimpresa á espensas de un cura de esta diócesis, con las licencias necesarias de esta Sagrada 
En 1758 se imprime el Catecismo mexicano de Gerónimo de Ripalda, ${ }^{47}$ del también jesuita Ignacio de Paredes, quien traduce a la lengua náhuatl el catecismo de Ripalda y agrega la "Doctrina pequeña dispuesta por el P. Bartholomé Castaño de la Compañía de Jesús", ${ }^{48}$ con 26 preguntas y respuestas. ${ }^{49}$ La diferencia entre este cuestionario y el contenido dentro de los manuscritos de Lucas Matheo reside igualmente en que Paredes no presenta preguntas especiales para explicar acerca de la virgen María y los ángeles. Él aumenta de 24 a 26 respuestas, para poner un mayor énfasis en el concepto de la explicación de la Santísima Trinidad.

Como pudo apreciarse, Gastelu (que no menciona a Castaño), Paredes (que contiene a Castaño) y el cuestionario del Egerton Ms. 2898 (atribuido a Castaño) son muy similares, aunque varían en el número de preguntas y respuestas.

Una posible explicación a lo que pudo haber sucedido para las variaciones entre uno y otro la encontramos en la "Razón de la obra al lector", que el jesuita Paredes añadió a su obra, ${ }^{50} \mathrm{y}$ en la que explica que tradujo a la lengua náhuatl el catecismo de Ripalda por ser el mejor y más adecuado en la materia y que en su traducción añadió algunas palabras utilísimas, como aconsejaba el poeta Horacio al traductor; "que en su versión, no tanto atienda â las palabras del original, quanto â lo que por las palabras se intenta decir". Esto y las variantes del náhuatl según las regiones, posiblemente hacen las diferencias del número de preguntas.

Paredes señaló que cuando él consideraba hacer alguna adición a lo que estaba en el original, ponía una marca (en forma de estrella), para mostrar que ésa era añadida por él, por creerla necesaria. Cabe hacer notar que no se encontró la mencionada marca para señalar sus adiciones en ninguna de las 26 preguntas y respuestas del cuestionario o doctrina

Mitra, quien lo dedica á beneficio de la clase indígena (Puebla: Imprenta de José María Rivera, 1860), última consulta 11 de julio de 2018, https://openlibrary.org/works/OL16523693W/ Catecismo_breve_que_precisamente_debe_saber_el_cristiano.

${ }^{47}$ Ignacio de Paredes, Catecismo mexicano Gerónimo de Ripalda (México: Imprenta de la Bibliotheca Mexicana, enfrente de San Agustín, Año de 1758), https://ia800603.us.archive.org/17/items/catecismomexican00ripa/catecismomexican00ripa.pdf, última consulta 11 de julio de 2018.

${ }^{48}$ Paredes, Catecismo mexicano, última consulta 11 de julio de 2018, https://ia800603. us.archive.org/17/items/catecismomexican00ripa/catecismomexican00ripa.pdf.

${ }^{49}$ Paredes, Catecismo mexicano, 143.

${ }^{50}$ Paredes, Catecismo mexicano, s/n. 
pequeña de Castaño. En atención a lo anterior, se puede suponer que lo copió fielmente.

Se buscó el catecismo de Castaño en alguna publicación posterior al siglo XVIII, y se encontró un artículo de Arnulfo Ariel de Santiago Gómez, ${ }^{51}$ en el que comenta la obra Catecismo de la doctrina cristiana en lengua otomí, traducida literalmente al castellano por el presbítero D. Francisco Pérez. En esta doctrina cristiana aparece el título mencionado por Galarza para el catecismo del Egerton Ms. 2898: Dialoguito de la palabra de Dios, del padre Castaño (cuestionario de 25 preguntas y respuestas), impreso a dos columnas, una en lengua otomí y en la otra la traducción al castellano. Pérez no brinda información respecto de si copió fielmente el "Dialoguito de Castaño".

Hasta la presente investigación no se pudo determinar cuál era el contenido original del padre Castaño, pero tal y como precisa Paredes, en las traducciones lo importante es que sean entendibles y no que sean fieles al original. Tal vez por eso, el mismo Castaño pudo haber tenido una versión en lengua otomí de 25 preguntas, otra de náhuatl con 24 y otra de 26 para alguna variante.

\section{LA AUTORÍA DEL CUESTIONARIO PARA LA CATEQUIZACIÓN CONTENIDO EN EL EGERTON MS. 2898}

La autoría del cuestionario del Egerton Ms. 2898, atribuida al jesuita Castaño, no puede entonces darse como absoluta. Según se observó, las cuatro preguntas y respuestas adicionales de nuestros catecismos, dedicadas a la virgen María y a los ángeles, no están contenidas dentro de los cuestionarios declarados como de Castaño por Paredes y Pérez. Ripalda ${ }^{52}$ es el autor de esas preguntas. Con base en lo anterior, el cuestionario del Egerton Ms. 2898 es una combinación de Ripalda y Castaño.

El cuestionario de catequización contenido en el Catecismo hispanomexicano era prácticamente idéntico al Egerton Ms. 2898 y, por esta razón,

${ }^{51}$ Arnulfo Ariel de Santiago Gómez, "Educar en el siglo XIX: Ediciones para culturas diferentes”, Intercultural Communications Studies XxI, n. 1, 2012: 61, https://web.uri.edu/ iaics/files/07ArnulfoUrielDeSantiagoGomez.pdf.

${ }^{52}$ Gerónimo de Ripalda, Catecismo y exposición breve de la Doctrina christiana por el P. M. Geronymo de Ripalda de la Compañía de Jesús (México: Imprenta del Nuevo Rezado, de Doña María de Ribera, en el Empredradillo, 1754), 45-46. Es una obra en castellano. 
se cotejaron ambos documentos en su totalidad. Se consideraban posiblemente relacionados, y la revisión a detalle era importante para tratar de identificar la relación.

\section{ANÁlisis de la firma del ESCRibano D. Locas Matheo EN EL EGERTON MS. 2898}

¿Por qué un indígena utilizó signos de escribano autorizado por el rey en su firma? Ni los indígenas ni los mestizos podían tener ese oficio autorizado por el rey, según la regulación novohispana. ${ }^{53}$

Como se observa en la figura 3, la firma del escribano hasta hoy identificado como D. Lucas Matheo no presenta los signos autorizados por el rey en el Códice Kaska (un Techialoyan de 1710), documento en el cual Burkhart lo identificó por paleografía. En contraste, en el Egerton Ms. 2898 para mostrar que estaba aprobado, necesitaba una firma de escribano autorizado por la Iglesia según las regulaciones señaladas en el apartado "Regulaciones para los catecismos manuscritos en lenguas originarias" de este trabajo.

Leticia Pérez Puente observó que la firma (véase la figura 4) contiene a dos personas. ${ }^{54}$ Lo anterior fue confirmado por Georgina Flores Padilla, experta en paleografía. ${ }^{55}$ Antes de la "D", se presenta el signo que significa

${ }^{53}$ Ivonne Mijares Ramírez, Escribanos y escrituras públicas en el siglo XVI. El caso de la Ciudad de México (México: Universidad Nacional Autónoma de México, Instituto de Investigaciones Históricas, 1997), 54.

${ }^{54}$ Cabe señalar que este punto generó cierta polémica en las revisiones del presente trabajo, porque hay puntos de vista diferentes. Uno de los dictaminadores anónimos del presente artículo emitió la observación que cito a continuación; "Es muy muy dudable que haya dos autores del Egerton 2898, y su único pedazo de evidencia, la supuesta marca 'otro sí' (v//), no convence. Esta marca no diga "otro sí” por fuerza; más bien, es como el inicio de un parágrafo, nada más. Aún más, la estructura completa de la firma hace un cuadro alrededor de un único nombre, y haría violencia a la lectura romper este cuadro tan demarcado". En mi opinión y hasta donde tengo conocimiento, el signo "otro sí" no expresa sólo un inicio de párrafo. Se puede observar en este mismo documento cómo el escribano lo usa al final del Egerton Ms. 2898, como un signo de adición en la firma y no está iniciando un párrafo. Existiendo esta controversia, dejo a criterio del lector la respuesta.

${ }^{55}$ Paleógrafa, técnico académico del Archivo Histórico de la Universidad Nacional Autónoma de México, profesora de la licenciatura en Archivonomía en la Escuela Nacional de Biblioteconomía y Archivonomía. Presento entre paréntesis una aproximación tipográfica del signo “otro sí”. Le agradezco. 


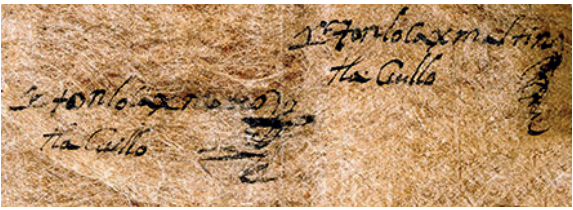

A

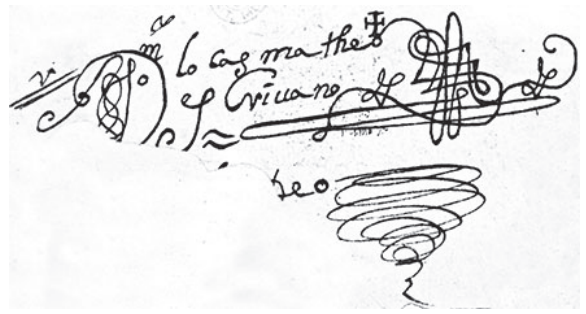

B

Figuras 3A y 3B. Comparación de la firma de Lucas Matheo

3A. Códice Kaska. Fotografía cortesía de The Hispanic Society of America 3B. Egerton Ms. 2898. Fragmento del folio 29v. (C) The Trustees of the British Museum

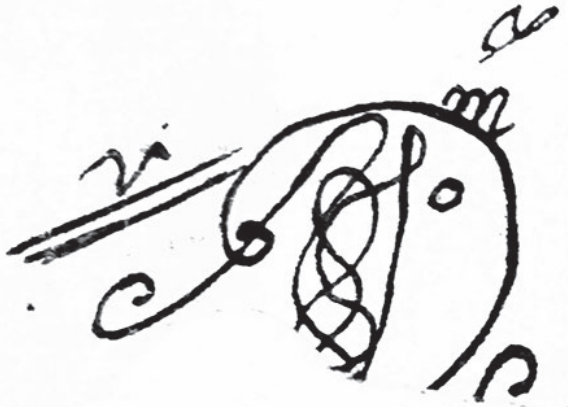

A

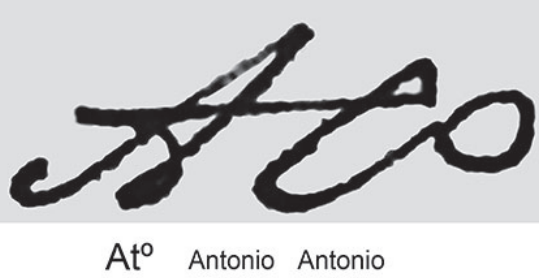

C

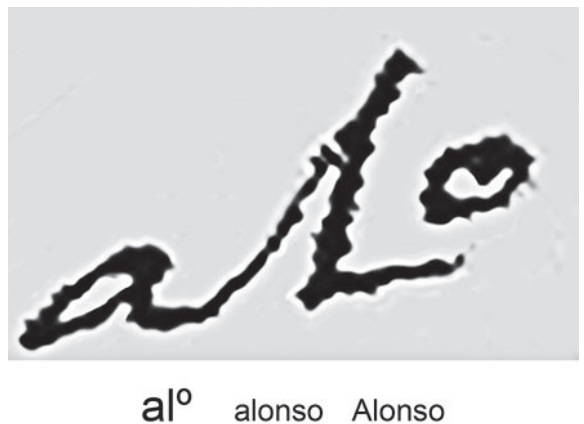

B

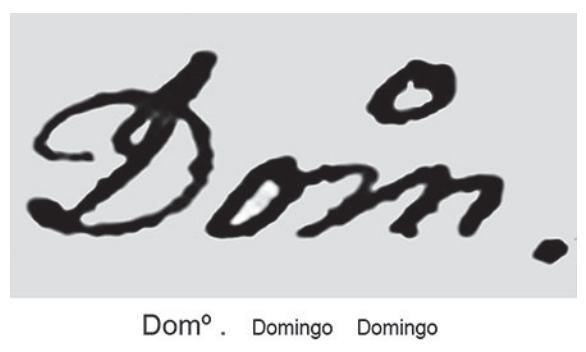

D

Figuras 4A, 4B, 4C y 4D. Detalle de la firma y abreviaturas del nombre posiblemente integrado. 4A. Detalle de la firma de Lucas Matheo. (C) The Trustees of the British Museum. 4B. Abreviatura novohispana del nombre Alonso. Diccionario de abreviaturas novohispanas Ak'ab tsi'b, proyecto digital (México: Universidad Nacional Autónoma de México, Instituto de Investigaciones Filológicas, 2013, iifilologicas.unam.mx/dicabenovo). 4C. Abreviatura novohispana del nombre Antonio. Diccionario de abreviaturas novohispanas. 4D. Abreviatura novohispana del nombre Domingo. Diccionario de abreviaturas novohispanas 
“otro sí” [v//]. En la "D” está integrada la abreviatura del nombre Alonso, o tal vez Antonio Dom[zínguez?] y por encima de la "m" de Dom, se lee una "y".

Siendo así, en realidad este documento tendría a dos personas que comparten el trabajo: “Alonso o Antonio Dom[zínguez?]” y "Locas Matheo escrivano", seguido de los signos y las marcas de escribano, conforme al uso identificador que poseían los escribanos autorizados por el rey.

Los signos de identificación de su firma son semejantes a los utilizados por los escribanos públicos y eclesiásticos adscritos a alguna escribanía de la ciudad de Antequera Oaxaca en la época colonial. ${ }^{56}$

Había indicios que sugerían la identidad indígena de nuestro escribano. Una de ellas es que firmaba como "Locas" por cuestiones de la pronunciación y no "Lucas" como habría firmado un escribano eclesiástico o escribano autorizado de acuerdo con la regulación novohispana.

Gaillemin ya encontraba una relación del Egerton Ms. 2898 con los Códices Techialoyan por datación y características, y proponía que era importante demostrar una participación activa en la catequización indígena. ${ }^{57}$ Margarita Menegus Bornemann establece que entre las características del escribano de indios estaba ser elegido por el gobierno de indígenas. ${ }^{58}$ Era importante que demostraran ser buenos cristianos y gozaran de un buen prestigio, sin que necesariamente fueran parte de la nobleza indígena. ¿Pero, por qué usó signos de escribano del rey?

La posible respuesta que sugiero es que era un escribano al servicio de los indígenas, de buen prestigio y muy apegado a la Iglesia. Encuentro probable entonces que algún sacerdote le hubiera solicitado que copiara integralmente este catecismo, cuyo deterioro ameritaba reposición y cuya firma con rasgos de escribano autorizado era importante para que continuara en uso. Sin embargo, el escribano no quiso pasar desapercibido y con el signo

${ }^{56}$ Moya y Rodríguez, "Signum notariae; la marca del escribano", Fundación Alfredo Harp Helu Oaxaca (blog), consultado el 2 de mayo de 2017, https://fahho.mx/blog/2017/05/02/ signum-notariae-la-marca-del-escribano/.

${ }^{57}$ Gaillemin, "L'art ingénieux", 679. Batalla Rosado también comenta el parecido de imágenes y la época de elaboración con los Techialoyan en su artículo "Problemática sobre la datación...", 53.

${ }^{58}$ Margarita Menegus Bornemann, La Mixteca Baja, entre la Revolución y la Reforma. cacicazgo, territorialidad y gobierno, siglos XVIII y XIX (México: Universidad Autónoma Benito Juárez de Oaxaca; Universidad Autónoma Metropolitana; H. Congreso del Estado de Oaxaca, 2009), 73-76, consultado el 8 de agosto de 2018, https://www.academia.edu/22487819/ La_Mixteca_Baja_ENTRE_LA_REVOLUCI\%C3\%93N_Y_LA_REFORMA. 
de "otro sí, inserta su nombre en el manuscrito, que comparte dos autorías: la del escribano eclesiástico que autorizó y la de él como escribano copista.

Es un hecho que existen documentos que son copiados por indígenas a petición de un superior, en los que incluso imitan firmas, según la experiencia de Flores Padilla.

El signo "otro sí", que se observa en la firma, significa adición y fue empleado correctamente por Locas Matheo. Este elemento fue lo primero que mostró la verdadera relación de los documentos, como se discute a continuación.

ESTUdio COMPARATIVO DEL EGERTON MS. 2898

Y EL CATECISMO HISPANO-MEXICANO QUE MUESTRA QUE AMBOS DOCUMENTOS PROVIENEN DE LA COLECCIÓN RAMÍREZ

Es muy importante resaltar que el Egerton Ms. 2898 es un catecismo pictográfico original y el denominado Catecismo hispano-mexicano es la copia del manuscrito náhuatl sin copiar imágenes, elaborado y traducido al español por Galicia Chimalpopoca.

Para este trabajo fueron comparados en su totalidad, desde el primero hasta el último folio. Observando la paleografía de Galicia Chimalpopoca del Catecismo hispano-mexicano se infieren los siguientes detalles:

1. La carátula de presentación del Catecismo hispano-mexicano, dice: "Catecismo Hispano-Mexicano por Lucas Mateo 19 Aug. 1714. Cópia Moderna por Prof. Galicia Chimalpopoca”. Esta carátula manuscrita difiere de la caligrafía del copista, por lo que pudo haber sido elaborada por algún comerciante bilingüe inglés-español, que presenta casi todo en español, excepto "Aug..." que es la abreviación en inglés para el mes de agosto. Quien elaboró la carátula lo denominó Catecismo hispano-mexicano por contener una columna en idioma castellano (hispano) y otra en náhuatl (mexicano), y así logró una presentación descriptiva del documento. Alguien más agregó en la parte superior de la carátula (caligrafía diferente) una identificación, tal vez para la Bancroft que dice: "Roman Catholic church. Catechisms//Aztec" (y una rúbrica). 


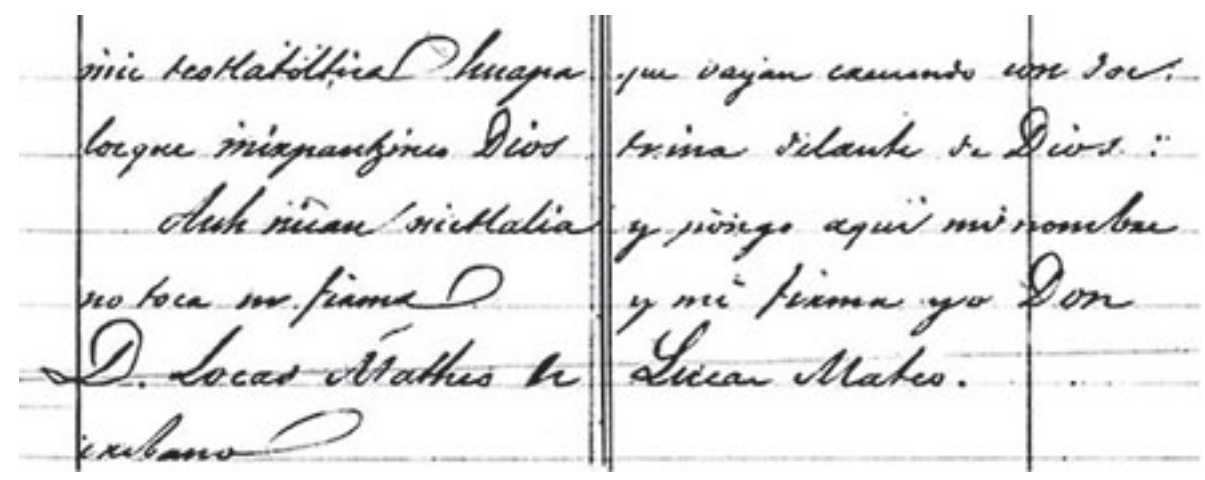

Figura 5. Detalle de la firma en el manuscrito Catecismo hispano-mexicano, f. 47. Bancroft Library, University of California, Berkeley, H. H. Bancroft Collection, Ms. M-M 465. Fotografía tomada por Luz María Tena Colunga de una copia proporcionada por el doctor Prescott Muir

2. En el texto final (figura 4), la columna en español originada ${ }^{59}$ por Galicia Chimalpopoca, ${ }^{60}$ presenta la firma según su interpretación; “Don Lucas Mateo”, y conserva “D. Locas Matheo” en la del náhuatl, cuya paleografía copió sin modificar.

3. La introducción del Catecismo hispano-mexicano comienza con el "Texto de la Doctrina Christiana" contenido en el Catecismo del jesuita Gerónimo de Ripalda que tuvo gran circulación desde su impresión en 1618 y se tradujo al náhuatl. ${ }^{61}$ Ésta comienza con "Todo fiel cristiano está muy obligado a tener devoción de todo corazón con la Santa Cruz”. Galicia Chimalpopoca la copió en su manuscrito (folios 1 al 5) del original que en ese entonces estaba completo. Según se infiere, al original le retiraron folios para desvincularlo y venderlo como si fuera más antiguo.

${ }^{59}$ Schwaller, "Guías de manuscritos en náhuatl”, 363. Comenta que Chimalpopoca Galicia frecuentemente traducía los documentos al español para Ramírez.

${ }^{60}$ Karen Dakin, Mercedes Montes de Oca y Claudia Parodi, Visiones del Encuentro de Dos Mundos en América: lengua, cultura traducción y transculturación (México: Universidad Nacional Autónoma de México, Instituto de Investigaciones Filológicas; Universidad de California en los Ángeles, Centro de Estudios Coloniales Iberoamericanos, 2009), 215. Faustino Galicia Chimalpopoca, según una semblanza de Angélica Guerra cambiaba el orden de sus apellidos en uno u otro de sus escritos. Si quería destacar su ascendencia indígena, firmaba como Chimalpopoca Galicia y si creía conveniente opacar ese detalle, firmaba como Galicia Chimalpopoca. En este manuscrito aparece como "Prof. Galicia Chimalpopoca".

${ }^{61}$ Ripalda, Catecismo y exposición breve de la Doctrina christiana. Sin numeración en esta edición. Son dos hojas la extensión de este texto. 
El fortalecimiento de esta idea se aprecia en el folio 1r del Egerton Ms. 2898 que comienza con una abreviatura de escribanía, que significa "otro sí” [v //], ${ }^{62}$ que es para indicar una adición (en este caso del escribano), la cual no sería necesaria para comenzar un texto introductorio.

Ahora bien, las pérdidas del texto manuscrito que tiene el Egerton Ms. 2898 las fue señalando Galicia Chimalpopoca en su trabajo, según se presenta en el siguiente cuadro (véase el cuadro 1).

Como se aprecia, el Egerton Ms. 2898 es el único catecismo original de D. Locas Matheo. Ramírez lo obtuvo para su colección y muy probablemente le pidió a Chimalpopoca Galicia que lo paleografiara y tradujera al español. Para ese entonces, ya el documento tenía muchas de las pérdidas que presenta actualmente y que fueron marcadas con líneas punteadas o dejando espacios en blanco, como se señaló anteriormente.

En el anexo 1 de este trabajo se presenta una cédula del cuestionario de evangelización, que elaboramos para su estudio a dos columnas: en la izquierda la paleografía normalizada del manuscrito en náhuatl y en la derecha, la traducción de los conceptos al español, como hipotéticamente se propone que eran percibidos por el indígena. Por ejemplo, en el caso de Santa María, utilizamos "siempre doncella", en lugar de traducir cemicac ichpochtzintli como "siempre virgen".

Lucas Matheo utilizó las siguientes abreviaturas: ${ }^{63}$

- S. ${ }^{\text {to }}$, S. $^{\text {ta }} \rightarrow$ Santo, Santa.

- to $^{\circ} \rightarrow$ Totecuyo.

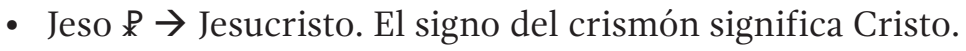

Estas abreviaturas se observan igualmente en la copia de paleografía que hizo Galicia Chimalpopoca en el Catecismo hispano-mexicano, quien normalizó el náhuatl a la usanza del siglo xix y es prácticamente igual a la normalización que se presenta en este trabajo.

En la cédula que presentamos se separan las preguntas y respuestas, de acuerdo con cada folio y considerando cada cuadro de diálogo, señalando también a qué página de lectura corresponden, a manera de facilitar su localización en el catecismo pictográfico. Chimalpopoca no hace esa separación.

${ }^{62}$ Entre corchetes puse una aproximación a lo que se observa en el manuscrito de ese signo de escribanía.

${ }^{63}$ No se presentan en la columna del náhuatl (anexo 1), porque se desataron para normalizarlas. 


\section{Cuadro 1 \\ Folios del CATECisMo HisPano-MEXiCANo, QUE MUESTRAN PÉRDIDA DE MANUSCRITO, TAL Y COMO SE OBSERVA EN EL EGERTON MS. 2898}

Folio 8:

Chimalpopoca transcribe: "Y cuando ya" del folio 3r del Egerton Ms. 2898 y deja la idea inconclusa en el manuscrito. Esto se debe a que la idea de la muerte sólo se expresó en imagen en el folio 2v (correspondiente al Ave María) del Egerton Ms. 2898.

Folio 13:

Correspondiente a los mandamientos del folio 8r del Egerton Ms. 2898. Sólo se presenta el primero, el segundo, el quinto y el noveno en el manuscrito completo. El manuscrito enuncia "El sexto no..." y el concepto se complementa con la imagen de la pareja de indígenas (tapados con un cobertor) que indica acción sexual. Por último, presenta el cierre incompleto del decálogo. Hay pérdida total del tercero, cuarto, séptimo, octavo y décimo.

El folio 8r del Egerton Ms. 2898 permite verificar con mayor rapidez (confrontando con el folio 13 del Catecismo hispano-mexicano) que Chimalpopoca paleografió y tradujo al español el Egerton Ms. 2898.

Folio 32:

Se señalan con línea punteada varias pérdidas en el manuscrito del folio $20 \mathrm{v}$ del Egerton Ms. 2898. Chimalpopoca corrige el nombre de Gabriel, que en el Egerton Ms. 2898 dice Grabiel (otra señal de la mano indígena de D. Locas Matheo, que al igual que algunos indígenas contemporáneos, pronuncian mal ese nombre). En esta sección del Rosario, normalizó y corrigió varias palabras. Otro ejemplo es "Ave María” que estaba como "Aben María”.

Folio 33:

Igualmente, señala la pérdida de manuscrito del folio 21v del Egerton Ms. 2898 con línea punteada.

Folio 34:

El folio 22r del Egerton Ms. 2898 actualmente presenta una pequeña pérdida de manuscrito en esta sección del Rosario, que no la señala como pérdida Chimalpopoca. Tal vez no estaba perdida cuando la copió, o tal vez la supo inferir.

Folio 35:

Transcripción del folio 23r del Rosario en el Egerton Ms. 2898. Chimalpopoca señaló con línea punteada las pérdidas e infirió una pequeña partícula de una palabra al inicio, que está perdida en el Egerton Ms. 2898, o que tal vez sí estaba cuando lo copió.

Folio 36:

Corresponde todavía a una parte del folio 22v del Rosario en Egerton Ms. 2898, y tiene señalada la pérdida de manuscrito con línea punteada. 
Cuadro 1. Continuación...

Folio 37:

Transcripción del Rosario folio 24r del Egerton Ms. 2898. Chimalpopoca señala con línea punteada que no está completa la idea en lengua manuscrita.

Folio 39:

En el folio 24v del Rosario del Egerton Ms. 2898 se tiene perdida una porción del manuscrito en náhuatl, pero Chimalpopoca no lo presenta como pérdida. Era fácil de inferir, porque es la indicación del rezo del Padre Nuestro y Ave María, así que tal vez sólo lo completó, o puede ser que se haya perdido después.

Folio 40 y 41 :

Última sección del Rosario, folio 26r del Egerton Ms. 2898. Las pérdidas de manuscrito las señala Chimalpopoca con línea punteada.

Folio 42:

Chimalpopoca inicia con las obras de misericordia del folio 27r del Egerton Ms. 2898. En la imagen se observa pérdida del manuscrito y se presenta con línea punteada en el Catecismo hispano-mexicano.

Folio 43:

Presenta con línea punteada lo que se perdió en el folio 28r del Egerton Ms. 2898.

Folio 44:

En esta ocasión, la pérdida correspondiente en imagen y manuscrito del folio $27 \mathrm{v}$ del Egerton Ms. 2898 es de las Bienaventuranzas de los que padecen. Simplemente la deja con un espacio en blanco.

Folio 45:

Copia del folio 28v, correspondiente al Confiteor del Egerton Ms. 2898. Las pérdidas las presenta con espacio en blanco y también con línea punteada.

Folio 46:

Continua el Confiteor del folio 29r del Egerton Ms. 2898 y las pérdidas las presenta con línea punteada.

Folio 47:

Prosigue la transcripción de los folios 29r, 29v y 30r del Egerton Ms. 2898. Presenta con línea punteada las pérdidas del manuscrito.

Respecto del folio 29v del Egerton Ms. 2898, es ahí donde, después del Confiteor, encontramos la fecha y la firma. Chimalpopoca copió la fecha en que D. Locas Matheo terminó el Egerton Ms. 2898; "En 19 de agosto de 1714". En ese entonces estaba completa. 


\section{CONSIDERACIONES FINALES}

Los datos obtenidos en la presente investigación aportan elementos que confirman la autenticidad del Egerton Ms. 2898. Según se expuso: Schwaller, en su "Guía de manuscritos", establece que proviene del Museo Nacional, lugar en donde Ramírez y Chimalpopoca corroboraron este manuscrito, contra la copia elaborada por ellos (Catecismo hispano-mexicano). De la Torre Villar asevera que Ramírez aprovechaba, como conservador y director del Museo Nacional, su puesto de interventor de las bibliotecas y archivos de los conventos extinguidos para acrecentar su documentación. Atento a lo anterior, se desprende que Ramírez aparentemente tuvo el original para copiarlo, cotejarlo y estudiarlo. Hasta el momento, no se tienen bases para determinar cómo pasó a formar parte de la Colección Ramírez. Del análisis se infiere que ambos documentos estuvieron juntos en las manos de alguno de los vendedores de libros raros, quien decidió separarlos y desvincularlos para obtener un mayor beneficio económico. El Museo Británico no lo catalogó como proveniente de la Colección Sánchez-Solís. Se encuentra probable que el vendedor que los descontextualizó los haya tenido en lotes separados.

La desvinculación de ambos documentos provocó que actualmente estén en diferentes repositorios y que por más de un siglo, únicamente se hayan considerado como "Dos catecismos del siglo XVIII elaborados por D. Lucas Matheo”, posiblemente relacionados por el año de elaboración y el nombre del escribano.

Se considera, por todos los elementos puestos a consideración en esta investigación, que el Egerton Ms. 2898 es un catecismo original que estuvo en uso, y es factible que estuviera en un colegio de la orden jesuita, tanto por la autoría jesuita del cuestionario de evangelización, como por la imagen de instrumentos musicales utilizados por esa misma orden, mostrada en la figura uno. El manuscrito se elaboró en 1714 y la expulsión de los jesuitas ocurrió en 1767. Por esta razón, es posible que el documento haya formado parte de los archivos de los conventos extinguidos. Sin embargo, como señalamos en su oportunidad, se necesitan datos contundentes para poder afirmar a qué orden perteneció, dado que contiene imágenes tales como la figura del sacerdote, que tiene parecido con el hábito de la orden de predicadores dominicos. 
En las regulaciones vigentes del siglo XviII se menciona que los indígenas podían poseer sus propias doctrinas cristianas en manuscrito, siempre y cuando éstas estuvieran autorizadas para su circulación. Sin embargo, es evidente que éste no fue el caso del Egerton Ms. 2898, que al parecer pudo haber sido propiedad de algún convento extinguido, intervenido por Ramírez.

Lucas Mateo se identifica en español como "escribano" en el catecismo Egerton Ms. 2898 y en el Códice Kaska Techialoyan como tlacuilo, palabra náhuatl que significa escribano, pero también pintor o dibujante. No tenemos la certeza de que él haya elaborado las imágenes de los códices en los que aparece su firma.

Como comentamos en su oportunidad, se emprendió la búsqueda de identificación del documento a través de la firma y la confirmación de la doble identidad (Alonso o Antonio Dom[zinguez?] /Lucas Matheo) contenida en el Egerton Ms. 2898, tanto en expedientes históricos del Archivo General de Notarías como en el Archivo General de la Nación. Sin embargo, no todas las acciones de los escribanos eclesiásticos quedaron registradas en esos archivos, por lo que en un futuro sería recomendable revisar en los expedientes históricos de los siglos XVII y XVIII firmas de escribanos eclesiásticos de las diócesis. Encontramos posible que la firma del escribano eclesiástico Alonso o Antonio Dom[¿ínguez?] se encuentre en algún archivo histórico del marquesado del Valle, considerando que los signos identitarios de la firma se parecen a los de los escribanos de esa región.

En futuras líneas de investigación, se podría intentar conseguir algún documento manuscrito de Bernard Quaritch, Henry Stevens o Edward Ayer y comparar la caligrafía con la de la carátula del Catecismo hispanomexicano, que parece haber sido elaborada por algún comerciante de libros raros, para una indagación más profunda del manejo de la venta de la Colección Ramírez.

En un futuro trabajo sería recomendable revisar los otros dos manuscritos, que Normann clasificó dentro de su Grupo Egerton, y que consideró copias realizadas tomando como base al Egerton Ms. 2898, con la finalidad de identificar si todo el grupo formó parte de la Colección Ramírez. ${ }^{64}$

${ }^{64}$ Normann, “Testerian Codices”, 129 y 150. 


\section{ANEXO 1}

CÉDUla DE DiÁLOGO EN NÁHUATL NORMALIZADO Y TRADUCCIÓN EN ESPAÑOL DE LOS CONCEPTOS COMO SE PROPONE QUE ERAN PERCIBIDOS POR LOS INDÍGENAS PARA SU COMPRENSIÓN

Página 1 de lectura

(f. $13 v$ y $14 r)$
$(S)=$ Sacerdote

(I)=Indígena 1er. Cuadro de diálogo:

(S) 1. Tla xihualmohuica in titeotlaneltocacatzin in totecuyo Dios tla xinechilhui; ¿Cuix onmoetztica in Teotl Dios?

(I) Ca quemacatzin, ca onmoetztica in Teotl Dios.

2o. Cuadro de diálogo:

(S) 2. ¿Auh quezquintin in teteo?

(I) Ca zan cetzin. In huel nelli Teotl Dios.

3er. Cuadro de diálogo:

(S) 3. ¿Auh campa moetztica inon Teotl Dios?

(I) Ca ompa moetztica in ilhuicatl itic ihuan in nican tlaltipac. In nonhuian cemanahuac moetztica.

4o. Cuadro de diálogo:

(S) 4 . Auh aquin oquimochihuilli in ilhuicatl ihuan in tlaltipactli?

(I) Ca yehuatzin, in totecuyo Dios.

5o. Cuadro de diálogo:

(S) 5 . ¿Auh ac yehuatzin in totecuyo Dios?

(I) Ca yehuatzin in santisima trinidad. 1er. Cuadro de diálogo:

(S) 1. Ven tú, creyente en nuestro señor Dios, dime: ¿Acaso existe Teotl Dios?

(I) En verdad, sí. Existe el Teotl Dios.

2o. Cuadro de diálogo:

(S) 2. ¿Y cuántos dioses hay?

(I) Sólo hay uno. El muy verdadero Teotl Dios.

3er. Cuadro de diálogo:

(S) 3. ¿Y dónde está este Teotl Dios?

(I) Está allá en el cielo y aquí en la tierra. Está en todas partes del mundo.

4o. Cuadro de diálogo:

(S) 4. ¿Quién hizo el cielo y la tierra?

(I) Él, nuestro señor Dios.

5o. Cuadro de diálogo:

(S) 5. ¿Y quién es nuestro señor Dios?

(I) Él es la santísima trinidad. 
Anexo 1. Pagína 1. Continuación...

Página 1 de lectura

(f. $13 v$ y $14 r)$
$(S)=$ Sacerdote

(I)=Indígena 6o. Cuadro de diálogo:

(S) 6. ¿Auh ac yehuatzin in santísima trinidad?

(I) Ca yehuatzin, in Dios tetatzin, Dios tepiltzin, Dios espíritu santo. 6o. Cuadro de diálogo:

(S) 6. ¿Y quién es la santísima trinidad?

(I) Es Él, Dios padre, Dios hijo, Dios espíritu santo.

\section{Notas}

a) Se tomó la decisión de iniciar la palabra Teotl con mayúscula en toda la normalización del catecismo a fin de dar la misma importancia a la grandeza de esa palabra para la concepción indígena. La traducción "Dios Dios" no transmitiría lo que percibía el indígena y por ello, conservamos Dios Teotl o Teotl Dios.

b) Traducimos el "Ca yehuatzin" que es muy respetuoso, como "Él" en mayúsculas, con la intención de enfatizar el respeto.

c) Es curioso que las palabras "santísima" y "espíritu" no inician con mayúscula. Se respetó en eso la paleografía. Más adelante "santissima" tiene doble "s", como se podrá apreciar.

Página 2 de lectura

(f. $14 v$ y $15 r)$
$(S)=$ Sacerdote

(I)=Indígena 1er. Cuadro de diálogo:

(S) 7. ¿Auh in Dios tetatzin?, ¿cuix

Dios?, ¿cuix Teotl?

(I) Ca quemacatzin, ca Dios, ca Teotl.

2o. Cuadro de diálogo:

(S) 8. ¿Auh in Dios tepiltzin?, ¿cuix

Dios?, ¿cuix Teotl?

(I) Ca quemacatzin,ca Dios, ca Teotl.

3er. Cuadro de diálogo:

(S) 9. ¿Auh in Dios espiritu santo?, ¿cuix Dios?, ¿cuix Teotl?

(I) Ca quemacatzin, ca Dios, ca Teotl. 1er. Cuadro de diálogo:

(S) 7. ¿Y Dios padre?, ¿acaso es Dios?, ¿acaso es Teotl?

(I) Sí, es Dios, sí es Teotl.

2o. Cuadro de diálogo:

(S) 8. ¿Y Dios hijo?, ¿acaso es Dios?, ¿acaso es Teotl?

(I) Sí, es Dios, sí es Teotl.

3er. Cuadro de diálogo:

(S) 9. ¿Y Dios espíritu santo?, ¿acaso

es Dios?, ¿acaso es Teotl?

(I) Sí, es Dios, sí es Teotl. 
Anexo 1. Pagína 2. Continuación...
Página 2 de lectura
$(S)=$ Sacerdote
(f. $14 v$ y $15 r)$
(I)=Indígena

4o. Cuadro de diálogo:

(S) 10. ¿Auh cuix yeintin in teteo?

(I) Ca amotzin.

Macihui in yeintintitzin personasme teotlaca tzitzinti ca zanatzin in huel nelli Dios Teotl.

Yeica ca mochintinzitzin quimo pielia inza ceiuhcayotl inin netlamachtiltzin.

5o. Cuadro de diálogo:

(S) 11. ¿Auh ac yehuatzin in oquichtzintli omochiuhtzinoco in nican tlalticpac?

(I) Ca yehuatzin inic ome personas in intlazopiltzin Dios, in tictoyeitenehuilia in totecuyo Jesucristo.

6o. Cuadro de diálogo:

(S) 12. ¿Auh ac yehuatzin in totecuyo Jesucristo?

(I) Ca yehuatzin in huel nelli teotl ihuan huel nelli oquichtzintli.

7o. Cuadro de diálogo:

(S) 13. ¿Auh ac ytechpa oquich... $\rightarrow$ 4o. Cuadro de diálogo:

(S) 10. ¿Son tres los teteo (dioses)?

(I) No.

Aunque son tres personas divinas, sólo uno es el muy verdadero Dios Teotl.

Porque todos están en él. Tienen un carácter único, como atributo.

5o. Cuadro de diálogo:

(S) 11. ¿Y quién es el que vino a hacerse hombre aquí en la tierra?

(I) Es él, la segunda persona, el hijo querido de Dios, al que llamamos nuestro señor Jesucristo.

6o. Cuadro de diálogo:

(S) 12. ¿Y quién es nuestro señor Jesucristo?

(I) Es el muy verdadero Teotl y muy verdadero hombre.

7o. Cuadro de diálogo:

(S) 13. ¿Y de quien...[continúa en la página 3 de lectura]

\section{Notas}

a) Añadimos teteo, porque observamos que el escribano necesitaba esta palabra náhuatl en singular y en plural, para que comprendiera el indígena. De otra forma habría escrito "Dioses". Cabe mencionar que en la respuesta a esta pregunta primero se usa el préstamo del castellano "personasme" y posteriormente teotlaca en náhuatl.

b) Amotzin es diminutivo de amo, y no se puede reflejar en la traducción. 
Anexo 1. Continuación...

Página 3 de lectura

$(S)=$ Sacerdote

(f. $15 v$ y $16 r$ )

(I)=Indígena

1er. Cuadro de diálogo:

1er. Cuadro de diálogo:

(S) $13 \rightarrow i$...tzintli omochiutzinoco

(S) $13 \rightarrow i$...vino a hacerse hombre

in itlazopiltzin Dios, in

nican tlaticpac?

(I) Ca itechpatzinco in cemicac

ichpochtzintli santa maría

omonacayotitzinoco itictzin ca

ichpochxilantzinco ica

inteotlamahuizoltzin espiritu santo.

el hijo querido de Dios, aquí en la tierra?

(I) En la siempre doncella santa maría, se vino a encarnar en su vientre de doncella, por la divinidad maravillosa del espíritu santo.

2o. Cuadro de diálogo:

2o. Cuadro de diálogo:

(S) 14. ¿Auh ac yehuatzin, in cemicac ichpochtzintli santa maría?

(I) Ca yehuatzin, in Dios itlazonantzin in aic oquimolpohui in ichpochyotzin in motemiltitica gracia ihuan itetzinco catqui in nepapan iqualtihuani in ilhuicatl itic ihuan nican tlalticpac tlatoca cihuapilli santa maría.

3er. Cuadro de diálogo:

(S) 15. ¿Auh campa moetztica inon tlatoca cihuapilli santa maría?

(I) Ca ompa moetztica in ilhuicatl itic. Ica itlactzin, ihuan inianimantzin totepan tlatlatlauhticatzinmochiutzinnotica in ixpantzinco santíssima trinidad.

4o. Cuadro de diálogo:

(S) 16. ¿Auh tlein iquipampa oquichtzintli omochiutzinoco in itlazopiltzin Dios in nican tlalticpac?

(I) Ca topampa in titlatlacohuanime. Inic techmomaquixtilizin in nican tlalticpac.

(S) 14. ¿Y quién es ella, la siempre doncella santa maría?

(I) Ella es la muy amada madre de Dios, que nunca dejó de ser doncella y que está llena de gracia $y$ de todas las virtudes. En el cielo $y$ en la tierra es la reina doncella santa maría.

3er. Cuadro de diálogo:

(S) 15. ¿YY dónde está esta reina siempre doncella santa maría?

(I) Está allá en el cielo.

Con su cuerpo, su ánima está pidiendo y rogando por nosotros ante la santíssima trinidad.

40. Cuadro de diálogo:

(S) 16. ¿Y para qué se vino a hacer hombre el querido hijo de Dios aquí en la tierra?

(I) Por nosotros los pecadores.

Para salvarnos aquí

en la tierra. 
Anexo 1. Pagína 3. Continuación...

Página 3 de lectura

(f. $15 v$ y $16 r$ )
$(S)=$ Sacerdote

(I)=Indígena 5o. Cuadro de diálogo:

(S) 17. ¿Auh tlein oquimochihuili in totecuyo Jesucristo in nican tlalticpac inic otechmomaquixtili?

(I) Ca topampa omotlayohuilti itencopa omochiuh in Poncio Pilato inic crosti. 5o. Cuadro de diálogo:

(S) 17. ¿Y qué hizo nuestro señor Jesucristo aquí en la tierra para salvarnos?

(I) Por nosotros sufrió por orden de Poncio Pilato en la cruz.

Notas

a) En el 1er. cuadro de diálogo: "inteotlamahuiçoltzin" se tradujo como la "divinidad maravillosa" considerando que "tlamahuizolli" es maravillar y que el prefijo tiene la connotación de ser algo que tiene divinidad.

Página 4 de lectura

(f. $16 v$ y $17 r$ )
$(S)=$ Sacerdote

(I)=Indígena 1er. Cuadro de diálogo:

(I) $17 \rightarrow$ Techomamazohualtiloc omomiquili ihuan no tococ omotemohui in mictlan.

2o. Cuadro de diálogo:

(I) Yeilhuitica in omozcalitzino in intlan in mimicque omotlecahui in ilhuicatl itic omotlalitzinoto imayecancopatzinco in initlazotatzin Dios in ixquich ihuelitzin.

Occepa ompa hual motemohuiz quin mo tlatzontequiliquiuh in yolque.

Ihuan in mimicque.

3er. Cuadro de diálogo:

(S) 18. ¿Auh in totecuyo Jesucristo?, tla xinechilhui $i$ cuix omomiquili inic Teotl, anozo inic oquichtzintli?

(I) Ca amotzin, camo ma omomiquili inic teotl ca zan ixquich inic oquichtzintli omomiquili. 1er. Cuadro de diálogo:

(I) $17 \rightarrow$ Murió crucificado por nosotros y también fue sepultado $y$ descendió al mictlan.

20. Cuadro de diálogo:

(I) A los tres días resucitó de entre los muertos, subió al cielo, y fue a sentarse a la derecha de su amado padre Dios todopoderoso.

Y por segunda vez bajará para venir a juzgar a los vivos. $Y$ a los muertos.

3er. Cuadro de diálogo:

(S) 18. ¿Y nuestro señor Jesucristo?, dime... ¿acaso murió como Teotl, o como hombre?

(I) No, no murió como Teotl, nada más murió como hombre. 
Anexo 1. Página 4. Continuación...
Página 4 de lectura
$(S)=$ Sacerdote
(f. $16 v$ y $17 r)$
(I)=Indígena

4o. Cuadro de diálogo:

(S) 19. Auh in tlalticpac tlacatl iniquac miqui; ¿̇cuix ihuan miqui inianiman in iuh miqui in itlalnacayo?

(I) Ca amotzin, camo miqui inianiman cazan ixquich in itlalnacayo miqui.

5o. Cuadro de diálogo:

(S) 20. $i$ Auh cuix cemicac miqui in itlalnacayo?

(I) Ca amotzin, yeica ca in iquac inic in quimonequiltiz Dios in tlamic cemanahuatl in mochihuaz in tetlatzontequiliz ilhuitl. $\rightarrow$ 4o. Cuadro de diálogo:

(S) 19. Y los hombres de la tierra, cuando mueren; ¿̇Acaso también muere su ánima, así como muere su cuerpo terrenal?

(I) No, no muere su ánima, nada más su cuerpo terrenal.

5o. Cuadro de diálogo:

(S) 20. ¿Y acaso muere para siempre su cuerpo terrenal?

(I) No, entonces cuando quiera

Dios que se acabe el mundo, se hará el día del juicio final. $\rightarrow$

\section{Notas}

a) La respuesta de la pregunta 20 termina hasta el primer cuadro de diálogo de la página 5 de lectura.

Página 5 de lectura (f. $17 v$ y $18 r)$
$(S)=$ Sacerdote

(I)=Indígena 1er. Cuadro de diálogo:

(I) $20 \rightarrow$ Ca oc cepa mocetiliz mozcaliz in tetlanalcayo ihuan cemicac yoliztli.

2o. Cuadro de diálogo:

(S) 21. $\dot{z}$ Auh in qualtin yectin in iquac momiquilizque campa yaz inin yolia in animan?

(I) Ca ompa

Yazque ilhuicatl itic in

itlatocachantzinco Dios. 1er. Cuadro de diálogo:

(I) $20 \rightarrow$ otra vez se reunirá, crecerá su cuerpo terrenal en la vida eterna.

2o. Cuadro de diálogo:

(S) 21. ¿Y los buenos y los rectos cuando mueran?, ¿a dónde irá su yolia, su ánima?

(I) Pues allá.

Irán al cielo, a la casa del tlahtoani Dios. 
Anexo 1. Página 5. Continuación...
Página 5 de lectura
$(S)=$ Sacerdote
(f. $17 v$ y $18 r)$
(I)=Indígena

(S) 22. ¿Auh quexquichcahuitl... $\rightarrow$

(S) 22. ¿̇Cuánto tiempo... $\rightarrow$ [sigue en 3er. Cuadro de diálogo]

3er. Cuadro de diálogo:

3er. Cuadro de diálogo:

(S) In ompa yesque in ilhuicatl, itic in itlatocachantzinco Dios?

(I) Ca cemicac ompa itloctzinco inahuactzinco monemiltizque in Dios yeica ca huel, oquipixque in iteotenahuatiltzin Dios ihuan in santa iglesia católica romana.

(S) $\rightarrow$...Allá estarán en el cielo, en el reino de Dios?

(I) Para siempre, allá al lado de Dios vivirán, porque guardaron el mandamiento de Dios y de la santa iglesia católica romana.

4o. Cuadro de diálogo:

4o. Cuadro de diálogo:

(S) 23. ¿Auh in amo qualtin in amo yectictin campa in quinmotlatzacuiltiliz Dios?

(S) 23. Y los que no son rectos, ¿̇a dónde los encerrará Dios?

(I) Ca ompa in centlani mictlan.

(I) Allá en lo más profundo del mictlan.

Tlayohuiltilozque ompa cemicac yezque yeica camoloquipixque in iteotenahuatiltzin Dios.

Sufrirán, allá para siempre estarán, porque no cumplieron el mandamiento de Dios.

5o. Cuadro de diálogo:

(S) 24. ¿Auh tlein quitoznequi santa iglesia católica romana?

5o. Cuadro de diálogo:

(S) 24. ¿Y qué quiere decir santa iglesia católica romana?

(I) Ca quitoznequi teoyotica in ne centlatiliz in ixquichtin in

(I) Quiere decir la reunión religiosa de todos los cristianos ... $\rightarrow$

\section{Notas}

a) En la paleografía original, santa iglesia católica romana no fue escrito con mayúsculas al inicio de la palabra, por lo que se determinó conservarlo así. En el caso de Dios, siempre está con mayúscula al inicio.

b) La secuencia de diálogo para la respuesta a la pregunta 24 termina en el primer cuadro de diálogo de la sexta página de lectura. 
Anexo 1. Continuación...
Página 6 de lectura
$(S)=$ Sacerdote
(f. $18 v$ y $19 r)$
(I)=Indígena

1er. Cuadro de diálogo:

(I) $24 \rightarrow$ In teotl aneltocanime in tzontecontzin mochiuhtzinotica in totecuyo Jesucristo.

2o. Cuadro de diálogo:

(S) 25. Auh tla xinechilhui in angelome ¿ac yehuantinzintzin?

(I) Ca centlamantintzintzin yoliliznecuiltonoliz espiritutzintzin ihuan cemicac necuiltonoliz cuicatica quimoyecte nehuilitzinohua in Dios, in ompa in ilhuicatl itic.

3er. Cuadro de diálogo:

(S) 26. ¿Auh cuix zan ixquich in intequitzin?

(I) Ca amotzin, ca ihuan icoquinmixquechili in Dios inic totepantlatocatzitzin ihuan totemachticatzitzin.

Ihuan inic huel ipan totlatocazque in iteotenahuatiltzin Dios, ihuan in iquac inye tomiquiliztenpan, techmomanahuilizque techmomaquixtilizque, in ihuicpa in toyauh in tlacatecolotl.

4o. Cuadro de diálogo:

(S) 27. Auh tla xinelchihui ¿Ac yehuatzin onca moetz... $\rightarrow$ 1er. Cuadro de diálogo:

(I) $24 \rightarrow$ creyentes en dios cuya cabeza es nuestro señor Jesucristo.

2o. Cuadro de diálogo:

(S) 25. Y dime, los ángeles, ¿quiénes son ellos?

(I) Es una reunión de espíritus alegres que regocijarán para siempre con cantos y alabanzas a Dios, allá en el cielo.

3er. Cuadro de diálogo:

(S) 26. ¿ Y ese es todo su trabajo?

(I) No, porque también (con esto) Dios les encargó que fueran nuestros defensores (abogados) y nuestros maestros.

$Y$ entonces, podremos seguir los mandamientos de Dios, y en el momento que estemos al borde de la muerte, nos van a proteger, nos van a salvar, de nuestro enemigo el hombre-búho.

4o. Cuadro de diálogo:

(S) 27. Dime, ¿Quién es el que...

\section{Notas}

a) La pregunta 27 continua en el primer cuadro de diálogo de la séptima página de lectura. 
Anexo 1. Continuación...
Página 7 de lectura
$(S)=$ Sacerdote
(f. 19v y 20r)
(I)=Indígena

1er. Cuadro de diálogo:

1er. Cuadro de diálogo:

(S) ...27 $\rightarrow$ tica in Santíssimo

$(\mathrm{S}) . .27 \rightarrow$ está en el Santíssimo

Sacramento?

(I) Ca yehuatzin onca moetztica in Sacramento?

(I) Pues el que está allí es el hijo itlazopiltzin Dios in totecuyo Jesucristo, in huel nelli Dios Teotl in quenin moetztica in ilhuicatl itic, ca zan noyuhqui in nican tlaltipac in nonhuian cemanahuac moetztica. querido de Dios, nuestro señor Jesucristo, el muy verdadero Dios Teotl, así como está en el cielo, en la tierra y por todas partes del mundo.

2o. Cuadro de diálogo:

20. Cuadro de diálogo:

(S) 28. ¿Auh tlein ticchihuazque in nican [tlalticpac] inic huel [timomaquixtizque]?

(I) Ca ticpiezque in matlactel in iteotenahuatiltzin Dios ihuan in santa iglesia católica romana.

(S) 28. ¿Y qué haremos aquí en la tierra para salvarnos?

(I) Guardaremos los diez mandamientos de Dios y los de la santa iglesia católica romana.

3er. Cuadro de diálogo:

3er. Cuadro de diálogo:

(S) 29. ¿Auh tlein quichihuaz in cristiano in cristiana inic huel qualli quimoceliliz in Santíssimo Sacramento?

(S) 29. ¿Y qué hará el cristiano y la cristiana para poder recibir bien el Santísimo Sacramento?

(I) Ca inic qualli quimoceliliz nezahualiztica, ihuan neyolcuitiliztica, tlamacehualiztica ipampa azo itla, itech ca in animan in temictianitlatlacolli.

(I) Para poder recibirlo bien, es con ayuno, con confesión, con penitencia, por si acaso su alma está en un estado de pecado mortal.

Ma in Mochihua

Así sea.

\section{Notas}

a) En el 2o. cuadro de diálogo, por deterioro, el manuscrito presenta ausencia de palabras en náhuatl, por lo que para normalizar el diálogo, se escriben las palabras tlalticpac y timomaquixtizque, que se adivinan por lógica. 


\section{FUENTES}

Repositorios documentales consultados

Archivo General de Notarías, Catálogo de Protocolos del Archivo General de Notarias de la Ciudad de México, Fondo Antiguo 1525-1902.

Archivo General de la Nación, México: Instituciones Coloniales, Gobierno Virreinal, SE045 Escribanos, Escribanos Reales, Escribanos Eclesiásticos, Escribanos de Provincia y Escribanos de Número, Fecha(s) 1600-1841.

\section{Bibliografía}

Aubin, Joseph Marius Alexis. Memorias sobre la pintura didáctica y la escritura figurativa de los antiguos mexicanos, 1a. reimp. México: Universidad Nacional Autónoma de México, Instituto de Investigaciones Históricas, 2009.

Batalla Rosado, Juan José. "Problemática sobre la datación de los catecismos en pictogramas o códices testerianos." En Del saber ha hecho su razón de ser... Homenaje a Alfredo López Austin. V. 2, ed. de Ángela Ochoa y Eduardo Matos Moctezuma. México: Instituto Nacional de Antropología e Historia/Universidad Nacional Autónoma de México, 2017.

Berger, Uta. Gebetbücher in mexikanischer Bilderschrift: Europaische Ikonographie im Manuskript Egerton 2898 aus der Sammlung des Britischen Museum, London. Münster: LIT, 2002.

Berger, Uta. Mexican Painted Manuscripts in the United Kingdom. Occasional Paper, n. 91. Londres: British Museum, 1998.

Boone, Elizabeth Hill, Louise M. Burkhart y David Tavárez. Painted Words: Nahua Catholicism, Politics and Memory in the Atzaqualco Pictorial Cathecism. Washington, D. C.: Dumbarton Oaks, 2017.

Burkhart, Louise M. "2014 Presidential Address: Christian Salvation as EthnoEthnohistory: Two Views from 1714.” Ethnohistory 63, n. 2 (abril 2016). DoI: https://doi.org/10.1215/00141801-3455267.

Burkhart, Louise M. "The 'Little Doctrine' and Indigenous Catechesis in New Spain.” Hispanic American Historical Review, n. 94 (2014).

British Museum Catalogue of Additions to the Manuscripts 1911-1915, 2 v. Londres: British Museum, 1925.

Dakin, Karen, Mercedes Montes de Oca y Claudia Parodi. Visiones del Encuentro de Dos Mundos en América: lengua, cultura traducción y transculturación. México: Universidad Nacional Autónoma de México, Instituto de Investigaciones Fi- 
lológicas/Universidad de California en Los Ángeles, Centro de Estudios Coloniales Iberoamericanos, 2009.

Escalante, Thomás de. Breve noticia de la vida exemplar y dichosa muerte del venerable padre Bartholomé Castaño en la Compañía de Jesús. México: Juan Rivera en el Pedradillo, 1679.

Gaillemin, Bérénice. "L'art ingénieux de peindre la parole et de parler aux yeux. Élaboration et usages des catéchismes en images du Mexique (xvie-XIxe siècles).” Tesis de doctorado en Etnología. París: Université Paris Ouest Nanterre La Défense, 2013.

Galarza, Joaquín. Doctrina christiana: Méthode pour l'analyse d'un manuscrit pictographique mexicain de XVIIIe siècle, avec application à la première prière le Pater Noster. Con la colaboración de Aurore Monod Becquelin. París: Société d'Ethnographie, 1980.

Glass, John B. "A Census of Middle American Testerian Manuscripts." En Handbook of Middle American Indians 14/15. Guide to Ethnohistorical Sources, Parts Three and Four. Edición de Robert Wauchope, Howard F. Cline, Charles Gibson, H. B. Nicholson. Texas: University of Texas Press Austin, 1975.

Holley, Edward G. Reseña de American Rare Book Dealer in London (1845-1886), de Henry Stevens of Vermont. Disponible en http://hdl.handle.net/2142/37740.

León-Portilla, Miguel. Cantares mexicanos I: Estudios. México: Universidad Nacional Autónoma de México/Fideicomiso Teixidor, 2011.

León-Portilla, Miguel. La filosofía náhuatl estudiada en sus fuentes, 10a. ed. México: Universidad Nacional Autónoma de México, Instituto de Investigaciones Históricas, 2006.

Martínez López-Cano, María del Pilar, coord. Concilios provinciales mexicanos. Época colonial. México: Universidad Nacional Autónoma de México, Instituto de Investigaciones Históricas, 2004. Disponible en: http://www.historicas.unam. $\mathrm{mx} /$ publicaciones/publicadigital/libros/concilios/concilios_index.html.

Mendieta, fray Gerónimo de. Historia eclesiástica indiana. 1a. reimp. México: Consejo Nacional para la Cultura y las Artes/Ediciones Cien, 2002.

Menegus Bornemann, Margarita. La Mixteca Baja, entre la Revolución y la Reforma. Cacicazgo, territorialidad y gobierno, siglos XVIII y XIX. México: Universidad Autónoma Benito Juárez de Oaxaca/Universidad Autónoma Metropolitana/H. Congreso del Estado de Oaxaca, 2009. https://www.academia.edu/22487819/ La_Mixteca_Baja_ENTRE_LA_REVOLUCI\%C3\%93N_Y_LA_REFORMA.

Mijares Ramírez, Ivonne. Escribanos y escrituras públicas en el siglo XVI. El caso de la Ciudad de México. México: Universidad Nacional Autónoma de México, Instituto de Investigaciones Históricas, 1997. 
Moya, Lérida, y Socorro Rodríguez. "Signum notariae: la marca del escribano." Fundación Alfredo Harp Helu Oaxaca (blog). https://fahho.mx/blog/2017/05/ 02/signum-notariae-la-marca-del-escribano/.

Normann, Anne Whited. "Testerian Codices: Hieroglyphic Catechisms for Native Conversion in New Spain." PhD diss. Tulane University, New Orleans, 1985.

Palomera, Esteban J., S. J. Fray Diego Valadés, ofM, evangelizador humanista de la Nueva España. El hombre, su época y su obra. México: Universidad Iberoamericana, Departamento de Historia, 1988.

Paredes, Ignacio de. Catecismo mexicano de Gerónimo de Ripalda. Tradujo del castellano al mexicano Ignacio de Paredes. México: Imprenta de la Bibliotheca Mexicana, enfrente de San Agustín, Año de 1758. https://ia800603.us.archive. org/17/items/catecismomexican00ripa/catecismomexican00ripa.pdf.

Ripalda, Gerónimo de. Catecismo y exposición breve de la doctrina christiana por el P. M. Geronymo de Ripalda de la Compañía de Jesús. México: Imprenta del Nuevo Rezado, de Doña María de Ribera, en el Empredradillo, 1754. https://ia800603. us.archive.org/17/items/catecismomexican00ripa/catecismomexican00ripa.pdf. Santiago Gómez, Arnulfo Ariel de. "Educar en el siglo XIx: ediciones para culturas diferentes". Intercultural Communications Studies xxI, n. 1 (2012). https://web. uri.edu/iaics/files/07ArnulfoUrielDeSantiagoGomez.pdf.

Schwaller, John Frederick. "Guías de manuscritos en náhuatl conservados en The Newberry Library (Chicago), The Latin American Library of Tulane University, The Bancroft Library, University of California, Berkeley." Estudios de Cultura Náhuatl, n. 18 (1986).

Torre Villar, Ernesto de la. "Vida y obra de José Fernando Ramírez." En Obras históricas, I. Época prehispánica de José Fernando Ramírez. México: Universidad Nacional Autónoma de México, Coordinación de Humanidades, Instituto de Investigaciones Históricas, 2001. http://www.historicas.unam.mx/publicaciones/publicadigital/libros/obras_historicas/oht01/388_04_02_VidaObra.pdf. Vázquez Gastelu, Antonio. Catecismo breve que precisamente debe saber el cristiano. Reimpresa á espensas de un cura de esta diócesis, con las licencias necesarias de esta Sagrada Mitra, quien lo dedica á beneficio de la clase indígena. Puebla: Imprenta de José María Rivera, 1860. https://openlibrary.org/works/OL16523 693W/Catecismo_breve_que_precisamente_debe_saber_el_cristiano.

Zulaica Gárate, Román. Los franciscanos y la imprenta en México en el siglo XVI. México: Universidad Nacional Autónoma de México, Instituto de Investigaciones Bibliográficas, 1991. 